\title{
INSIDE THE BLACK BOX OF THE CORPORATE STAFF:
SOCIAL NETWORKS AND THE IMPLEMENTATION OF CORPORATE STRATEGY
}

\author{
ADAM M. KLEINBAUM ${ }^{1 *}$ and TOBY E. STUART ${ }^{2}$ \\ 1 Tuck School of Business, Dartmouth College, Hanover, New Hampshire, U.S.A. \\ ${ }^{2}$ Haas School of Business, UC Berkeley, Berkeley, California, U.S.A.
}

\begin{abstract}
In multidivisional firms, the corporate staff is central to the implementation of corporate-level strategy, but empirical evidence on its function is limited. We examine one corporate staff through e-mail analysis. We find sharp cross-sectional differences in communication patterns: staff members have networks that are larger, more integrative, and richer in structural holes. However, much of this difference is attributed to sorting processes, rather than being caused by employment in the corporate staff per se. Further, once people receive the 'corporate imprimatur,' they retain aspects of it even when they move back to the line organization. These results imply that the literature's emphasis on structure as a means to achieve coordination undervalues a selection process in which individuals with broad networks match to coordination-focused jobs in the corporate staff. Copyright (c) 2013 John Wiley \& Sons, Ltd.
\end{abstract}

\section{INTRODUCTION}

The corporate staff is central in classical and contemporary theories of the multidivisional corporation. Indeed, the raison d'être for the diversified corporation is the creation of value through the coordination of activities, broadly defined, across multiple business units (Chandler, 1990). Research identifies multiple avenues through which the corporate center may create value (Goold and Campbell, 1987), virtually all of which entail some aspect of coordination within the firm. Yet, we know very little about coordination across the internal boundaries of the diversified firm.

For two reasons, we find it remarkable that this question has received limited attention in current, empirical research in the field. First, throughout

Keywords: corporate headquarters; corporate strategy; social networks; organizational structure; causal analysis *Correspondence to: Adam M. Kleinbaum, Dartmouth College, Tuck School of Business, Hanover, NH 03755, U.S.A. E-mail: adam.m.kleinbaum@tuck.dartmouth.edu the past century, the diversified, multidivisional corporation, or M-form, has become the primary organizational structure in the global economic landscape (Fligstein, 2001). The hallmark of the M-form is the oversight of the dispersed activities of the firm by a central headquarters unit (Chandler, 1962; Williamson, 1975). Well over half of all industrial output is produced in such organizations (Collis, Young, and Goold, 2007; Villalonga, 2004), and for many years, the vast majority of Fortune 500 firms have been diversified across multiple industries (Montgomery, 1994). This increasingly appears to be true in developing economies as well (Khanna and Palepu, 2000), and there is every reason to believe that globalization will only accelerate this trend. Moreover, there is reason to suspect that corporate-level strategy explains systematic differences in firm performance (Bowman and Helfat, 2001). Simply put, the limited empirical work on this subject belies its fundamental importance to the strategic management of the modern enterprise. 


\section{A. M. Kleinbaum and T. E. Stuart}

The second reason we consider this subject to be under-studied is that although the empirical literature on the corporate headquarters unit is sparse, it is appropriately central in current theories of the firm. In scholarship on the potential for value creation in the diversified firm, headquarters is regarded as the one organizational unit with the formal authority to gather information from, distribute information to, and coordinate symbiotic interactions among otherwise independent operating units (Chandler, 1962; Goold and Campbell, 1987; Penrose, 1959). Moreover, headquarters also possesses the power to determine the grouping of activities into formal organizational units; it houses the office of the chief executive; it exercises the major voice in the determination of overall corporate strategy; and it controls decision rights regarding the scope of the firm (Ansoff, 1965). Together with associated corporate staff functions, the headquarters coordinates the activities of the various business units (Collis et al., 2007; Goold, Campbell, and Alexander, 1994). In other words, our theories of the multibusiness corporation ascribe a vital set of tasks to the corporate-level staff, which fundamentally influence the conduct and outcomes of the primary organizational actors in the contemporary economy (Foss, 1997).

Given the importance of corporate staff, there is a mismatch in the limited empirical work that systematically examines its functioning. The few studies include work by Collis, Young, and Goold (2007), who report survey results on the cross-sectional relationship between headquarters size and the corporate strategy and governance systems of hundreds of companies in multiple geographies, demonstrating significant variation in the size and activities of the CHQ unit across geographies and corporate-level strategies. In the international business literature, there has been some work on the functions of headquarters in multinational corporations, with particularly influential contributions by Sumantra Ghoshal and colleagues (e.g., Ghoshal and Bartlett, 1990; Ghoshal, Korine, and Szulanski, 1994; Nohria and Ghoshal, 1994).

To begin to fill this gap, we conduct a quantitative case study set in a large, multidivisional company. We study the headquarters unit and a corporate-level staff function, the corporate sales force, which has an explicit mandate to coordinate across the subunits of the company. We analyze two temporally spaced cross sections from an electronic mail dataset comprising the correspondences of thousands of employees distributed across the organizational units of the company. These data allow us to compare the intrafirm communication networks of members of corporate headquarters (CHQ) and of the corporate sales force (CSF) to those of individuals in the line organization and, more broadly, to map the social organization of the M-form. ${ }^{1}$ To the extent that coordination is a central activity in the functioning of the corporate center, we would expect to observe that members of corporate staff units, on average, have broader, more organizationally integrative communication networks that are richer in structural holes than members of the operating units. We empirically demonstrate that this is indeed the case: members of the corporate center do have networks that appear to be better optimized for coordinating across disparate organizational and social structures than do employees in the line organization.

To our knowledge, the finding that corporate staff members possess networks that appear to be well suited for coordination has never been systematically documented, though this result may not be surprising in and of itself. The thrust of our analysis focuses on the sources of the difference-and its implications for the implementation of corporate strategy. The conventional wisdom would attribute the broader networks of corporate staff members to formal structure: people are assigned to integrative roles in the corporate staff and the task requirements of those jobs then dictate their interaction patterns. Because the task structure of the headquarters is integrative, the argument goes, occupancy of corporate staff roles should itself cause differences in network structure. There is, however, an alternative possibility. In a more person-centered account, individual differences in ability or inclination to interact broadly would lead people of a certain

\footnotetext{
${ }^{1}$ Although our analysis will separately examine the corporate headquarters unit and the corporate-level sales force, throughout the paper we will, for rhetorical convenience, refer to these two units as the 'corporate staff,' and we will frequently draw a contrast between 'staff' (i.e., employees of the CHQ and the $\mathrm{CSF}$ ) and employees who are members of the 'line' organization (i.e., any of the 29 business units of the company). Because we separately report all results for CHQ and CSF, however, we will empirically compare the findings for these two corporate-level units, and we will never constrain the regressions by estimating them on pooled data.
} 
type to be sorted or selected into staff roles. Therefore, it may be recruitment, selection, or matching processes - not an actor's position on the formal organization chart - that explain differences in the shapes of networks between members of the staff and the line.

Simply put, the question for the corporate strategist can be stated: are network structures suited for coordination achieved through staff positions per se or through selection of people with certain network configurations to positions in the corporate staff? This is a difficult empirical question to answer definitively, but we are able to gain some purchase on it because we can measure communication networks both before and after episodes of employee mobility in both directions across the staff-line divide (i.e., transitions from CHQ or CSF to a line role and from the line organization to a position in CHQ or CSF). When we couple data from communication networks with intervening mobility events, we can attempt to disentangle the person effects from the role effects. We do this by estimating regressions of the probability of staff-to-line and of line-to-staff transitions. These estimated probabilities of the conditional likelihood of mobility may account for endogeneity in estimating the effect of formal role on subsequent network structure.

The findings suggest operation of a selection process that results in the recruitment to the corporate staff of central individuals with broad networks that link others across business units. Thus, employees who have networks that are suited to disseminate information, influence others, and effect coordination are more likely to match to coordination-focused jobs at the corporate center. This is true for transitions from the line organization to both the corporate headquarters and the corporate sales force. Even after accounting for the selection process, however, we find evidence of an incremental effect of the corporate role on broadening individuals' networks. Therefore, we find that both person and role effects result in networks that are larger, less constrained, and more integrative across organizational units among people who switch into jobs in the corporate staff. We find no evidence, however, that exiting from jobs in the corporate staff is associated with a narrowing of social networks. Our results suggest that once people receive the 'corporate imprimatur,' they may carry it with them, even when they move back to the line organization.
Interestingly, we also show that the specific contacts in employees' networks quickly turn over following mobility events, but the overall topology of the network - the levels of centrality, structural holes, and cross-boundary integration-remain largely unchanged.

This research offers several contributions to the literature. Most importantly, our results challenge the conventional wisdom that the primary means to implement a coordination-based corporate-level strategy is through the formal structure of the corporate center alone. To the extent that social networks are a useful means of promoting coordination, our results suggest that positions in the corporate center do matter but that selection of the right people to occupy those positions is also crucially important. For corporate strategists, this suggests the need both for structural mechanisms and for policies that recruit individuals with the right 'types' of networks for these types of roles. As such, we suggest that research on social networks is more important to the study of strategy implementation than has heretofore been recognized. More generally, when we open the black box of the corporate center to reveal its internal wiring, the structures of the communication networks we observe appear to be consistent with the corporate center's role in effecting coordination. This supports a long-standing but undocumented assumption of the theoretical literature that highlights the unique role of the corporate center in implementing the coordination necessary to create value in the diversified firm.

\section{THEORY AND HYPOTHESES}

Three different activities link the behavior and structure of the corporate center with effective corporate control. First, in the multidivisional firm, the corporate staff oversees the formulation of corporate strategy, strategic planning, and resource allocation (Andrews, 1971; Bower, 1970). Second, in normative models of corporate-level advantage (e.g., Goold et al., 1994), the corporate center performs a series of value-creating activities, ranging from instituting centralized functions and lateral structures that ensure cross-business unit exploitation of economies of scale and scope, to enacting mechanisms that promote the transfer of knowledge across businesses, to the development, implementation, and transfer of core competences, to 


\section{A. M. Kleinbaum and T. E. Stuart}

the allocation of capital across the business portfolio. Third, in behaviorally oriented views, the corporate staff propagates shared values across the organization (Ouchi, 1980; Parsons, 1956). We believe that all these forms of coordination have similar implications for the social organization of the M-form: in performing these functions, members of the corporate staff necessarily engage in interactions across the many social and organizational boundaries within the company. Doing so effectively requires them to have larger, broader, farther-reaching networks of interactions than members of the line.

Why should this be? Their role in corporatelevel coordination requires members of the corporate staff to both gather and disseminate information throughout the organization. Doing so depends critically on the composition of the networks of members of the corporate center. Freeman describes network centrality as an indicator of the extent to which a person is 'in the thick of things' (Freeman, 1979: 219). Wasserman and Faust remark that central actors, as measured by degree scores, are "where the action is" in the network,' and thereby 'come to be recognized by others as a major channel of relational information' (Wasserman and Faust, 1994: 179). To the extent that members of the corporate staff do coordinate across the corporation, we should expect to find them to be 'in the thick of things' and to know 'where the action is' to a greater degree than members of the line organization. Central people may possess the range of contacts that enables them to facilitate smooth interactions across intraorganizational boundaries (Ghoshal et al., 1994). Likewise, people with high centrality in the internal network possess the ability to disseminate information and ideas to many colleagues and to mobilize coworkers to participate in coordinated undertakings. Therefore, we expect that members of the corporate staff, on average, will have higher centrality than members of the line organization.

As a relatively small unit tasked with coordinating across a large and diverse organization, the corporate center's success depends on efficient flows of information. The network structure that efficiently trades in information is thought to be one that is rich in structural holes (Burt, 1992). When a given individual interacts with other people, she is more likely to acquire new, nonredundant information when the two Alters are not themselves connected. The theory of structural holes rests on the premise that the absence of connections between one's contacts provides efficient access to a broad range of information. For this reason, we expect that the average corporate staff member will have more structural holes in her network than will the average member of the line organization. Additionally, to the extent that coordination occurs hierarchically (Chandler, 1962; Williamson, 1975) — with members of the line organization engaging in sequentially coordinated activities with no direct interaction, but only by implementing directives from the corporate staff - we would further expect to see more structural holes in corporate staff networks than in the networks of members of the line organization.

While a diverse network is useful for gathering information, the act of coordination may require more than just being situated between pairs of disconnected actors. In contemporary organizations, many scholars believe that interaction patterns often are characterized by free-flowing, lateral, and collaborative exchanges of information (Kogut and Zander, 1992; Powell, 1990). In this perspective, rigid hierarchies do not necessarily play the sole or even the dominant role in orchestrating coordination; rather, coordination occurs more organically and necessitates brokering ties between actors. And, considering the coordination-based mandate of the corporate staff, it specifically requires promoting communications among interactants who hail from disparate units of the organization.

Neither centrality nor structural holes necessarily address the specific task of the corporate center to coordinate between business units. In fact, in any sufficiently large group with low within-group network density (such as a typical strategic business unit in a large company), it is possible for individuals to have high centrality and many structural holes but to possess exclusively within-SBU contacts. Therefore, to assess the degree to which an individual's network is well suited to promoting coordination between business units, we introduce a measure of cross-boundary integration. A crossboundary integrator is an individual who brings together people in her network from different parts of the organization. By bringing together her contacts, the cross-boundary integrator participates in closed triads, or groups of three people in which each individual is connected to both of the other two. Closed triads have the property of promoting accountability because if one person behaves poorly toward another, their mutual acquaintance 
is likely to learn about it, thus damaging the offender's reputation (Simmel, 1902). Closed triads therefore are well suited for building collaborative norms and coordination (Coleman, 1988).

This conception of a cross-boundary integrator accords with prior research showing that individuals vary in their propensity to build integrative networks and that doing so is associated with involvement in coordination-intensive activities, such as innovation (Obstfeld, 2005). Because the unique role of the corporate center is to promote coordination between business units, we define crossboundary integration explicitly as communication activity that links two others from two different business units. We expect that, consistent with their role in promoting coordination across the enterprise, members of the corporate center will have more integrative networks, on average, than members of the line organization.

At first blush, it may seem that cross-boundary integration is incompatible with structural holes or that a high value on one implies a low value on the other. This is because a structural hole occurs when there is noncommunication among the members of Ego's network, whereas crossboundary integration arises when Ego's direct contacts interact with each other. Though network configurations in which an actor's contacts are disconnected result in efficient access to a broad range of disparate information by virtue of being linked to people who engage in different social circles, even brokers participate in some closed triads. For us, the pivotal question is which of the triads in a broker's network are closed? For an individual with low network constraint, when many of the remaining, closed triads in Ego's network comprise Alters who hail from different business units, Ego will have a network that is simultaneously high in structural holes within the business unit and integrative across business units. Because cross-boundary integration depends on specific group assignments of the Alters but the structural holes measure does not, the constructs are not incompatible. We argue that members of the corporate staff are likely to have both more integrative networks and more structural holes.

To summarize, we join theoretical arguments about the role of the corporate center in the multidivisional firm with the literature on social networks to offer the following baseline predictions about main effect differences between the networks of members of the corporate staff versus those of members of the line organization:

Baseline Hypothesis: Relative to otherwise comparable members of the line organization, employees in corporate staff units will have communication networks that exhibit (1) greater centrality, (2) more structural holes, and (3) more cross-boundary integration.

To be very clear about a core assumption of our argument, we assume that the occurrence of coordinated activities in the organization will leave a footprint in the social networks of the individuals who play pivotal roles in this process. We are not able to observe coordination directly, but if the assumption that its residue is apparent in the network structures of those who enact it is correct, we can infer the existence of coordination from network structures.

If we find support for the Baseline Hypothesis, the observed differences in network structure might arise for three very different reasons. The first is a structural or position-based explanation: as classical theorists would argue, the formal job responsibilities of members of the corporate staff lead them to communicate broadly across the many borders of the formal organization as they endeavor to coordinate and supervise activities that take place in disparate organizational locations. Although we know of no research that directly addresses the question of whether or precisely why members of the corporate staff should have broader networks than members of the operating units, most research on strategy implementation implicitly assumes such a position-based explanation. In their review of different perspectives on strategy implementation, for example, Bourgeois and Brodwin articulate the conventional view most clearly: 'Perhaps the most obvious tool for strategy implementation is for management to alter the structure of the organization. ... This has been the traditional approach espoused by most business policy textbooks,' (Bourgeois and Brodwin, 1984: 246). As a case in point, Galbraith and Nathanson entitle their textbook 'Strategy Implementation: Structure and Process,' and devote fewer than three pages to people or their careers (Galbraith and Nathanson, 1978: 86-88).

With specific regard to network formation, there are solid theoretical and empirical grounds upon which this conventional wisdom rests. A large 


\section{A. M. Kleinbaum and T. E. Stuart}

literature has shown that network formation is very much contingent on opportunities for convenient contact. Zipf (1949) argued that network connections are formed through the "principle of least effort.' Feld (1981) elaborated that whenever two people coparticipate in any kind of a 'social focus,' they are more likely to interact. More recent work confirms that proximity, whether social, organizational, or physical, greatly increases the likelihood of tie formation (Marmaros and Sacerdote, 2006). And within organizations, there is evidence that patterns of interaction very much are functions of the same proximity principles: individuals are far more likely to interact when they are located in the same physical place, when they share common interests, and when they are in the same organizational units (Kleinbaum, Stuart and Tushman, 2013).

If this perspective is correct, the shape of an individual's social structure is causally influenced by the position the individual occupies in the organization. We label this the position-based explanation for structural differences in network composition, and it implies that there is a causal effect of mobility into corporate staff jobs on the subsequent structure of individuals' networks:

Hypothesis 1: The greater centrality, more structural holes, and more integrative networks possessed by members of the corporate staff are causally related to individuals' formal roles in the organization (position-based explanation).

There is at least some evidence in the literature to suggest that position-based explanations may be insufficient to generate the kinds of networks needed for the corporate staff to implement coordinated initiatives. In research on boundary spanning (Allen, 1977; Tushman and Katz, 1980), for example, Nochur and Allen (1992) asked whether boundary-spanning roles can be successfully established through formal organizational structure. They found that when people were appointed to formal roles that required them to serve as liaisons between a corporate research lab and operating units, individuals engaged in more contact with the lab but failed to build additional connections to the operating units, relative to similarly qualified professionals who did not serve in formal boundaryspanning roles. In contrast, 'emergent' boundary spanners engaged in more contact both internally and externally. Thus, contrary to the conventional wisdom and to Hypothesis 1, the limited empirical evidence suggests that a position-based explanation alone may not fully account for the broader networks of members of the corporate staff.

This work suggests that individuals with preexisting networks that are suited to the task requirements of staff positions may match to jobs in the corporate center. Indeed, there is a long tradition of research showing significant selection effects in employment patterns based on ascribed and behavioral characteristics. Within the strategy domain, Gupta and Govindarajan (1984) argue that a business unit will implement its strategy more successfully when its general manager's prior experience and other personal characteristics (specifically, risk profile and tolerance for ambiguity) match the business unit's strategy (see also Lorsch and Morse, 1974). Incorporating these findings into a more comprehensive model, Govindarajan (1986) places selection of managers alongside formal organizational structure as distinct but essential administrative mechanisms for the effective implementation of different strategies in the SBUs of the diversified corporations.

Consistent with this work, it is possible that at the impetus of the individual, the firm, or both, people with broad, sparse, integrative networks that span intraorganizational boundaries will gravitate toward corporate staff positions. This would suggest that rather than, or in addition to, a causal effect of being in a corporate role on social network structure, there is an underlying sorting process that results in the assignment of individuals with broad social networks to staff positions. This would be particularly likely to occur if employees covet positions in the corporate staff as a means for career advancement. If this is the case and if individuals with broad networks are better able to compete for positions in the corporate staff, for this reason as well we would expect to find that individuals with structurally diverse networks are highly likely to move into jobs in the corporate staff. However, conditional on the matching process between individuals and jobs, there may be no additional, causal effect of organizational location (i.e., a staff job) on the structure of an individual's network:

Hypothesis 2: The greater centrality, more structural holes, and more integrative networks possessed by members of the corporate staff, relative to members of the line organization, are causally 
related to a selection process that sorts such people into the corporate staff (person-based sorting explanation).

Another, related possibility is that the selection process operates through a similar mechanism but in precisely the reverse direction: it may be that individuals in the corporate staff who fail to build broad networks choose to-or are encouraged to-depart staff roles to join the line organization, where the task environment is better suited to their smaller, more focused networks. If this were the case, we would expect to observe an effect of network structure on predicting the staff-line transition rate. Specifically, individuals with small, dense networks that forge few linkages between Alters from different business units should be more likely to move from jobs in the staff to assume positions in the line organization:

Hypothesis 3: The (1) lower centrality; (2) fewer structural holes; and (3) less integrative networks possessed by members of the line organization, relative to members of the corporate staff, are causally related to a selection process that sorts such people out of the corporate staff (personbased screening explanation).

In summary, if we find support for the Baseline Hypothesis, there are three alternative mechanisms that may account for the finding. In the first, there is a true effect of mobility into the corporate staff on the subsequent structure of individuals' networks. If we find evidence for Hypothesis 1 , it would underscore the widely perceived importance of formal position in the corporate staff on employees' ability to affect coordination and implement corporate strategy. If, however, we find support for Hypothesis 2 and/or 3, differences in network structure between members of the corporate staff and members of the line organization result in part from a sorting process that matches individuals with certain network characteristics to jobs. Thus, evidence supporting Hypothesis 2 or 3 would raise the possibility that selection of the right 'type' of people into corporate roles should accompany, or perhaps even supersede, the current emphasis on formal structure as the means through which corporate-level strategies are implemented across the boundaries within the diversified firm. This would suggest that the critical tasks of organization designers for the implementation of corporate strategy are not merely to create formal structures but also to understand differences in network structure at the individual level and to populate those formal structures accordingly.

\section{DATA, MEASURES, AND METHODS}

\section{Data}

We situate our analysis in the context of a company that, to preserve its anonymity, we will label 'BigCo.' BigCo is a large information technology company with 29 product divisions, organized into four primary product groups: hardware, software, technology services and business services. In recent years, the company has pursued a corporate strategy of integration among its many product and service offerings; correspondingly, promoting communication and coordination across formal organizational boundaries has been a priority for the company. Because of this focus on cross-corporate coordination, BigCo is a useful research site for studying the role of networks in effecting coordinated action (Eisenhardt, 1989).

The headquarters staff of BigCo includes C-suite executives and their staffs (CEO, CFO, CIO), corporate communications, human resources, the office of the general council and intellectual property protection, corporate marketing, and corporate strategy. The corporate sales force (CSF) is a stand-alone unit, separate from the corporate headquarters (CHQ), whose mandate is to coordinate across business units so that the company can deliver an integrated suite of products to provide solutions to customers' information systems needs. The organizational purpose of corporatelevel sales is to provide single points of contact at BigCo for each of the company's major customers, who purchase multiple, often interdependent, products and services. Members of the CSF are asked to work with the product units responsible for creating those products and services to ensure their interoperability. Although the activities of the CHQ and CSF staff are quite different, both organizational units stand outside the SBU structure and both possess explicit mandates to coordinate across the autonomous operating companies. Therefore, our analysis will (separately) compare the networks of members of 


\section{A. M. Kleinbaum and T. E. Stuart}

the line organization against those of members of the corporate headquarters and the corporate sales force.

The data we analyze include the complete internal e-mail record, as drawn from BigCo's servers, including 3.3 million dyadic communications among 23,689 employees during two observation periods: the fourth quarter of 2006 and the first quarter of 2008. All internal e-mail information that was on the server at the times of data collection was included in our dataset. To protect the privacy of individual employees, messages were stripped of all content, leaving only information about the sender, recipient(s) and time/date sent. The names of senders and recipients were replaced with encrypted identifiers. (Full details on how this sample was extracted from a larger dataset of 30,328 people and 268 million e-mails are provided in Appendix S1).

After cleaning and parsing these data, we collapse them into two cross-sectional panels separated by an interval of approximately one year. We treat these as separate cross sections and compute all network covariates based on a single sociogram that we construct for each of the two periods. For each window, we create a symmetric matrix with counts of, at the dyad level, the total number of $i \leftrightarrow j$ messages, where $i$ and $j$ index all individuals in the sample (Quintane and Kleinbaum, 2011; Wuchty and Uzzi, 2011). In the presentation of the results, we refer to these two cross sections as the Time 1 and Time 2 periods, respectively. In addition to the e-mail data, BigCo provided matching demographic and HR information. The HR data include each employee's business unit, major job function, job sub-function, tenure with the firm, salary band, U.S. state, and office location code. These are updated each month of the observation period and allow us to identify individuals who change jobs within the formal organizational structure.

\section{VARIABLES}

We focus on three general properties of individuals' communication networks during each of the two tranches of e-mail data: centrality within the intrafirm communication network, structural holes, and a novel measure we introduce called the 'matchmaker index.' To measure an employee $i$ 's centrality, we calculate degree centrality, the number of distinct Alters with whom the actor corresponds. Formally:

$$
\text { Centrality }_{i t}=\sum_{j=1}^{N} X_{i j t}
$$

where $i \neq j$ and $X_{i j t}=1$ when actors $i$ and $j$ exchange one or more e-mail correspondence during period $t$. In our models, we use the square root of degree, a transformation that improves model fit. $^{2}$

Structural constraint is an inverse measure of the presence of structural holes in an actor's network (Burt, 1992) and has been used widely throughout the strategy, management, and social network literatures. Actors with low structural constraint have networks in which their contacts are not themselves connected-that is, they possess networks with many structural holes. By contrast, highly constrained actors possess networks with dense, cliquelike connections among their direct contacts. Formally:

$$
\text { Constrain } t_{i t}=\sum_{j=1}^{N}\left(P_{i j t}+\sum_{k=1}^{N} P_{i k t} P_{k j t}\right)^{2}
$$

where $i \neq j$ and $P_{i j t}$ represents the share of actor $i$ 's communication ties that are exchanged with $j$ during period $t$ (i.e., $P_{i j t}=\frac{X_{i j t}}{\sum_{j=1}^{N} X_{i j t}}$ ). The inner summation incorporates the indirect constraint imposed on actor $i$ through connections among $i$ 's contacts; more such connections, and therefore more constraint, is tantamount to fewer structural holes in $i$ 's network. In our models, we use the natural logarithm of constraint, a common transformation that improves model fit. We use the StatNet package (Handcock et al., 2008) in the $\mathrm{R}$ statistical computing environment ( $\mathrm{R}$ Development Core Team, 2010) to calculate these network measures for each individual in the sample.

Finally, we introduce the 'matchmaker index' as a measure of cross-boundary integration (see Figure 1). Matchmakers facilitate relationships

\footnotetext{
${ }^{2}$ Although degree centrality is the simplest and most widely used centrality measure, our results do not depend on this choice; we find substantively similar results using eigenvector centrality (Bonacich, 1987), which is a weighted measure in which a focal actor's centrality depends not only on the number of people in her network, but also on their centrality scores.
} 
between disconnected actors who often are unaware of one another. In the spirit of the matchmaker, we construct an index of the extent to which each individual in the dataset facilitates interaction between Alters with two different organizational affiliations (business units, in our case). We operationalize the matchmaker index as the proportion of all closed triads in which a focal actor participates with two other people from two different business units. ${ }^{3}$ A triad is any set of three actors; a triad is closed when the focal individual, Ego, communicates with both of the other triad members, Alters, who, in turn, also communicate with one another. Ego has a high matchmaker index when many of the closed triads in which she participates consist of two Alters who are in different business units from one another. Actors with high matchmaker indices likely engage in coordination across business unit boundaries. In contrast, actors who participate in closed triads, primarily with members of the same business unit, would have low matchmaker indices and are likely to be more engaged in activities within, rather than across, boundaries. Formally, we define the matchmaker index as:

$M I_{i t}=\sum_{j=1}^{N}\left(\frac{\left(\sum_{k=1}^{N}\left(X_{i j t} \times X_{i k t} \times X_{j k t} \times x B U_{j k t}\right)\right)}{\left(\sum_{k=1}^{N}\left(X_{i j t} \times X_{i k t} \times X_{j k t}\right)\right)}\right)$

where $i \neq j \neq k$ and $x B U_{j k t}$, which differentiates the numerator of Equation 3 from its denominator, is equal to one when $j$ and $k$ are members of different business units in BigCo at time $t$.

Equation 3 bears some similarity to the 'honest broker index' (Borgatti, Everett, and Freeman, 2006) used in previous empirical work (e.g., Sasovova et al., 2010), in that both measures count the number of triads of a particular type in an egocentric network. It also resembles Gould and Fernandez's (1989) structures of mediation, in which Ego brokers interactions between two disconnected Alters who possess specific

\footnotetext{
${ }^{3}$ We calculate the matchmaker index using a proportion in order to avoid excessive correlation between the index and measures of network size. However, substantively identical results obtain if models are estimated using a simple count of the number of closed triads the focal actor shares with two people from two different business units (i.e., the numerator of Equation 3).
}
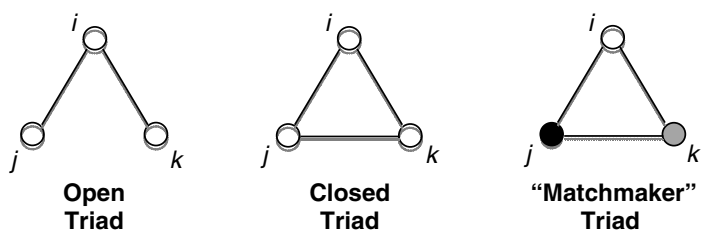

Figure 1. Illustrative diagram of open triads, closed triads and 'matchmaker' triads. A triad is a set of three individuals, $i, j$ and $k$, represented as circles. Interactions between them are represented as lines. (a) A triad is open from the standpoint of $i$ if $j$ and $k$ do not interact with one another, even if they both interact with $i$. (b) A triad is closed from the standpoint of $i$ if $j$ and $k$ interact with one another and they both interact with $i$. (c) A 'matchmaker' triad is a closed triad in which $j$ and $k$ belong to different business units from one another. In (c), nodes are shaded according to their business unit affiliations

group affiliations. The key substantive difference between both of these measures and our matchmaker index is that these are measures of brokerage and rely on the focal actor (the broker) mediating between Alters, who remain disconnected. The matchmaker index, by contrast, is about the focal actor bringing Alters together. For this reason, the spirit of our measure is closer to Obstfeld's (2005) work on an alternative model of brokerage that brings Alters together, rather than keeping them apart. ${ }^{4}$

BigCo also provided us with rudimentary career histories for the individuals in the dataset. We use these data to construct two variables indicating the number of times the person has moved job functions or office locations during the prior seven years of her BigCo career. We also include an individual's gender, tenure with the company, and a dummy variable indicating whether the person is an executive, defined as having salary grade above 10 on the firm's 14 -point scale..$^{5}$ The omitted

\footnotetext{
${ }^{4}$ It merits noting that our operationalization of the matchmaker index is independent of the unit affiliation of the matchmaker. We construct the variable this way to create comparability between the coordinative interactions of members of the line and the staff. To the extent that members of the line organization engage in coordination across units, it is likely to be between their own business unit and another unit. In contrast, the corporate staff might be effecting coordination between an individual operating unit and the corporate center or between two operating units. Our measure captures both types of cross-unit interactions.

${ }^{5}$ Unfortunately, we have no access to individual psychological variables, so we cannot rule out the possibility of unobserved heterogeneity in, for example, self-monitoring or empathy (Kleinbaum, Jordan, and Audia, 2012). However, the relatively high $R^{2}$ values in our first-stage models $(0.40)$ suggest that
} 


\section{A. M. Kleinbaum and T. E. Stuart}

category is middle manager, defined as having a salary grade from 7 to 10 ; recall that rank-and-file employees are excluded from our sample. Finally, we know the organizational and social networks only for the individuals in our sample. Although our data include all messages sent or received by these individuals, we do not know anything about the identities or organizational locations of senders and recipients outside of the sample. Therefore, we control for the percent of each individual's total e-mail communication volume that involves employees outside of the sample.

\section{ESTIMATION APPROACH}

We will begin the analysis with descriptive statistics of employees' networks broken out by staff versus line roles. We then estimate three sets of regressions. The first set explores cross-sectional differences in the three network characteristics between members of the corporate staff and the line organization and tests the Baseline Hypothesis. The distributions of two of the (transformed) dependent variables, degree centrality and structural constraint, are approximately normal, making ordinary least squares with robust standard errors an appropriate estimation choice. Because the matchmaker index is calculated as a proportion and is bounded between 0 and 1, we use fractional logit estimation (Papke and Wooldridge, 1996), also with robust standard errors. The covariate of interest is either $\mathrm{CHQ}$, a dummy variable set to 1 for individuals with positions in the corporate headquarters, or CSF, a dummy variable set to 1 for individuals with positions in the corporate sales force. In interpreting the CHQ and CSF dummy variables, all comparisons are to otherwise similar members of the line organization.

Next, we estimate a set of two-stage regressions that exploits the episodes of mobility across the staff and line divide to illuminate the mechanisms that generate the cross-sectional results and to test Hypotheses 1, 2 and 3. The first stage examines the effect of initial network position on the probability of mobility (Hypotheses 2 and 3), while the second stage examines the effect of endogenous mobility on subsequent network positions (Hypothesis 1).

the existing models with available data fit reasonably well, mitigating this concern somewhat.
Across both stages, we split the sample based on the location of individuals' origin jobs; for example, in models that include the variable LineTo-CHQ, we include all individuals who begin in the line and are therefore at risk of moving to CHQ.

In the first stage, we estimate four sets of probit models; in each, the dependent variable is a binary indicator of mobility across the line-staff divide. The four stage-one dependent variables are CHQ-to-Line, a dummy set to one if employee $i$ transitioned to the line organization before Time 2 , conditional on an origin job in CHQ; Lineto-CHQ, a dummy set to one if employee $i$ transitioned to CHQ before Time 2, conditional on an origin job in the line. Finally, CSF-to-Line and Line-to-CSF are constructed analogously to indicate mobility between the line organization and the corporate sales force.

The second-stage models examine the effect of (both directions of) $\mathrm{CHQ} \leftrightarrow$ line and $\mathrm{CSF} \leftrightarrow$ line mobility on characteristics of individuals' communication networks at Time 2. In these regressions, the three measures of communication network structure (degree centrality, structural constraint and the matchmaker index) serve as the dependent variables and the covariates of interest are the dummy variables indicating whether the focal actor made one of the four possible line $\leftrightarrow$ staff transitions in the one-year interval between the two tranches of e-mail data.

One can think of estimation of the effect of job mobility on communication network structure as a standard form of a treatment effect. Estimating the true effect of mobility across the line-staff boundary on network structure is challenging because of the general problem of nonrandom assignment of individuals to the treatment condition (i.e., mobility), which biases the estimate of the effect of mobility. The identification problem occurs because it is possible to observe the outcomes of interest for each individual either in the treatment (i.e., mobility) or the control (i.e., no mobility) condition, but not in both. Because we do not possess an instrumental variable that is exogenously associated with mobility, the best remaining option to address the nonrandom assignment problem is to employ a propensity score estimator (Rosenbaum and Rubin, 1984).

The propensity score for an individual $i$ is the conditional probability that $i$ is treated, given her 
vector of observable covariates. The propensity score may eliminate bias by comparing individuals in the treatment (i.e., mobility) and control (i.e., no mobility) conditions who have similar values of the observable, pretreatment covariates; that is, we compare people with similar ex ante propensities for mobility. The reliability of the propensity score, however, hinges on the (strong) assumption that outcomes are independent of assignment to treatment, conditional on observed covariates. If this is the case, matching estimators will yield unbiased estimates of the effect of mobility on network structure. The treatment effect for the treated population is defined (Dehejia and Wahba, 2002):

$$
\begin{aligned}
\left.\tau\right|_{T=1}= & E\left(\tau_{i} \mid T_{i}=1\right)=E\left(Y_{i 1} \mid T_{i}=1\right) \\
& -E\left(Y_{i 0} \mid T_{i}=0\right)
\end{aligned}
$$

where $T_{i}=1$ if individual $i$ is in the treatment group and 0 if in the control group. The difference:

$$
\tau^{e}=E\left(Y_{i 1} \mid T_{i}=1\right)-E\left(Y_{i 0} \mid T_{i}=0\right)
$$

is easily estimated but may be biased if the untreated outcome, $\mathrm{Y}_{i o}$ (in our case, properties of employee $i$ 's network) would differ for members of the treatment (movers) and control (stayers) groups. However, Rubin (1977) shows that if, given an observed covariate vector $\mathrm{X}_{i}$, it is the case that $\mathrm{Y}_{i 0}$ is independent of treatment status conditional on the observables $\mathrm{X}_{i}$, the treatment effect for the treated $\left.\tau\right|_{T=1}$ is identified and can be estimated with propensity scores. The intuition behind this approach is that if assignment to treatment is captured by the observed covariates, then the propensity score can be used to create a weighted (or matched) sample in which assignment to treatment is effectively random conditional on observables, thus approximating a controlled experiment.

Because the covariate vectors differ in each firststage regression (that is, each uses a different network covariate as well as the same vector of control variables), we calculate separate propensity scores corresponding to each regression and we trim from the sample the top 10 percent and bottom 10 percent of propensity scores. ${ }^{6}$ In our secondstage models, we could weight each observation

\footnotetext{
${ }^{6}$ Trimming removes treated observations with propensity scores that are higher or lower than those in the control group (that is, observations for which there are less good matches in the control group). Results are robust to a variety of different trimming rules.
}

by the inverse of its propensity score to create a pseudo-population that would give consistent, unbiased estimates of the treatment effect of mobility (Robins, 1999). However, if covariates are strongly associated with mobility, variability in propensity scores can result in extreme outlying values of the weighting factor; as a result, these outliers could contribute heavily to the pseudopopulation, giving the resulting estimator a large variance. The use of a stabilized weight alleviates this potential problem. The stabilized weight is calculated as the propensity score estimated on the full model divided by the propensity score estimated when excluding the covariate of interest (Azoulay, Ding, and Stuart, 2009). This modification does not affect the consistency of the estimator but does increase its efficiency (Hernán, Brumback, and Robins, 2000).

\section{RESULTS}

The majority of the sample is in the line organization in the Time 1 data and remains there throughout the observation window. In the data, there are 16,563 'stayers' in the line organization; 1,003 'stayers' in CHQ; and 4,841 'stayers' in Corporate Sales. A total of 110 employees begin in the line organization but move into CHQ at some point during the observation period and 35 travel in the reverse direction. We refer to these groups, respectively, as line-to-CHQ and CHQ-to-line switchers. A total of 546 people move from the line into the Corporate Sales force and 591 people move in the reverse direction. We refer to these as line-to-CSF and CSF-to-line switchers, respectively.

Table 1 reports a set of descriptive statistics to paint a portrait of e-mail communications within BigCo. The table shows that members of the corporate staff possess larger networks (125 contacts for CHQ, 139 for CSF) than members of the line organization (105). All three groups exchange a majority of messages with other members of their group (59.9\% for CHQ, $75.3 \%$ for CSF, $88.4 \%$ for the line), but when we consider the distribution of contacts (as opposed to emails) within versus beyond one's own group, the numbers shrink for all three groups $(31.6 ; 60.7$ and $80.6 \%$, respectively). Most strikingly, CHQ members have fewer than a third $(31.6 \%)$ of their communication partners within CHQ and nearly half $(46.8 \%)$ in the line organization. Members 
Table 1. Descriptive analysis of e-mail communications within BigCo at Time 1

\begin{tabular}{lccc}
\hline & CHQ & CSF & Line \\
\hline \# Employees & 1,069 & 5,456 & 17,442 \\
\# Contacts & 125 & 139 & 105 \\
$\%$ in CHQ & 31.6 & 3.8 & 3.6 \\
\% in CSF & 21.5 & 60.7 & 15.8 \\
\% in line & 46.8 & 35.5 & 80.6 \\
\# E-mails & 1,482 & 1,577 & 1,260 \\
$\%$ in CHQ & 59.9 & 2.3 & 2.0 \\
$\%$ in CSF & 13.5 & 75.3 & 9.6 \\
\% in line & 26.6 & 22.4 & 88.4 \\
\% multirecipient & 17.8 & 21.5 & 19.5 \\
\% recipients in multiple BUs & 7.6 & 7.1 & 5.9 \\
\hline
\end{tabular}

of the corporate staff also send a significantly $(\mathrm{p}<0.01)$ larger proportion of their e-mail to recipients in at least two different business units (7.6\% for CHQ, $7.1 \%$ for CSF; not significantly different from one another) than do members of the line $(5.9 \%)$. Summary statistics and correlations among Time 1 variables appear in Appendix S2.

Our description of the data proceeds with a set of cross tabulations. Table 2 describes the network positions of all individuals in the data, broken out by (1) whether the person remains in either a line or staff role between the two data collection windows, versus switches from the staff to the line or vice versa and (2) characteristics of their network positions in the two time periods. Comparing the upper left to the upper right quadrant shows, respectively, the Time 1 network positions of job 'stayers' and 'switchers.' The two lower quadrants of the table present exactly the same information but for the network in Time 2. (In this and all subsequent tables, variable names ending with '_1' are calculated using Time 1 data, corresponding to the fourth quarter of 2006, and ' 2 ' represents
Time 2 data, corresponding to the first quarter of 2008).

The primary conclusion from Table 2 is that job switchers in either direction across the line-staff boundary are more central in the corporate network and have less constrained, more integrative networks, compared to employees who remain within the line or the staff throughout both time periods. At Time 1 individuals who do not subsequently switch between staff and line roles between the two observation windows have lower degree centrality, fewer structural holes, and a lower matchmaker index than do switchers. The bottom two quadrants in the table reveal exactly the same patterns, but for the network in the Time 2 observation window. Of course, this table does not address the issue of causal ordering between mobility and the structure of individuals' networks.

Table 3 presents a similar set of cross tabulations, but this time we report network properties broken out by individuals' origin and destination roles; and we differentiate between the headquarters unit and the corporate sales force. To conserve space, we report only the Time 1 network descriptors because the patterns are identical in the Time 2 data. The top left quadrant in Table 3, Panel A describes the Time 1 network positions for individuals who were in line jobs in Time 1 and in Time 2 (i.e., stayers in the line organization). The lower right quadrant represents individuals in the headquarters in both time periods, and the off-diagonal quadrants represent individuals who moved from CHQ to line roles (upper right) and from jobs in the line to CHQ (lower left). Table 3, Panel B shows analogous descriptors about transitions between corporate sales and the line.

This table surfaces a number of points. First, the individuals who are most central in the communication network, highest in structural holes,

Table 2. Descriptive statistics by time period and by switcher status

\begin{tabular}{|c|c|c|c|c|c|c|c|}
\hline & \multicolumn{3}{|c|}{ Stayers } & \multicolumn{3}{|c|}{ Switchers } \\
\hline & & Mean & StDev & Median & Mean & StDev & Median \\
\hline \multirow{3}{*}{ Time 1} & Degree_1 & 112.02 & 96.37 & 87.00 & 144.79 & 95.74 & 122.00 \\
\hline & Constraint_1 & 0.027 & 0.044 & 0.015 & 0.014 & 0.013 & 0.010 \\
\hline & MatchmakerIndex_1 (\%) & 29.56 & 15.65 & 29.34 & 35.64 & 12.23 & 35.80 \\
\hline \multirow{3}{*}{ Time 2} & Degree_2 & 105.97 & 94.10 & 82.00 & 134.10 & 95.41 & 112.00 \\
\hline & Constraint_2 & 0.039 & 0.099 & 0.015 & 0.023 & 0.074 & 0.011 \\
\hline & MatchmakerIndex_2 (\%) & 33.85 & 16.21 & 33.80 & 43.34 & 12.24 & 43.00 \\
\hline
\end{tabular}


Table 3. Descriptive statistics of Time 1 network data by actors' Time 1 and Time 2 positions

Panel A: Switchers between positions in Corporate Headquarters and the line. The upper-left quadrant represents stayers-in-line; the lower left quadrant represents line-to-CHQ switchers; the upper right quadrant represents CHQ-to-line switchers; the lower right quadrant represents stayers-in-CHQ.

\begin{tabular}{|c|c|c|c|c|c|c|c|c|c|c|}
\hline & & & \multicolumn{4}{|c|}{ Actors in line at Time 1} & \multicolumn{4}{|c|}{ Actors in CHQ at Time 1} \\
\hline & \multicolumn{2}{|c|}{$\mathrm{CHQ} \leftrightarrow$ line transitions } & Mean & StDev & Median & $\mathrm{N}$ & Mean & StDev & Median & $\mathrm{N}$ \\
\hline \multirow{6}{*}{ Panel A } & \multirow{4}{*}{ Line in Time 2} & Degree_1 & 104.0 & 97.3 & 75 & & 139.2 & 81.1 & 127 & \\
\hline & & Constraint_1 & 0.031 & 0.049 & 0.017 & 16,786 & 0.0131 & 0.0096 & $5 \quad 0.0110$ & 30 \\
\hline & & MatchmakerIndex_1 (\%) & 27.79 & 16.03 & 27.25 & & 47.23 & 13.76 & 49.36 & \\
\hline & & Degree_1 & 138.8 & 95.8 & 119 & & 123.0 & 97.6 & 100 & \\
\hline & \multirow[t]{2}{*}{ CHQ in Time 2} & Constraint_1 & 0.016 & 0.015 & 0.011 & 103 & 0.018 & 0.018 & 0.013 & 1,016 \\
\hline & & MatchmakerIndex_1 (\%) & 36.52 & 15.66 & 37.76 & & 44.13 & 12.90 & 45.39 & \\
\hline
\end{tabular}

Panel B: Switchers between positions in the Corporate Sales Force and the line. The upper-left quadrant represents stayers-in-line; the lower left quadrant represents line-to-CSF switchers; the upper right quadrant represents CSF-to-line switchers; the lower right quadrant represents stayers-in-CSF.

\begin{tabular}{|c|c|c|c|c|c|c|c|c|c|c|}
\hline & \multirow{2}{*}{\multicolumn{2}{|c|}{$\mathrm{CSF} \leftrightarrow$ line transitions }} & \multicolumn{4}{|c|}{ Actors in line at Time 1} & \multicolumn{4}{|c|}{ Actors in CSF at Time 1} \\
\hline & & & Mean & StDev & Median & $\mathrm{N}$ & Mean & StDev & Median & $\mathrm{N}$ \\
\hline \multirow{6}{*}{ Panel B } & & Degree_1 & 104.0 & 97.3 & 75 & & 156.2 & 97.9 & 133 & \\
\hline & Line in Time 2 & Constraint_1 & 0.031 & 0.049 & 0.017 & 16,786 & 0.012 & 0.009 & 0.009 & 557 \\
\hline & \multirow{4}{*}{ CSF in Time 2} & MatchmakerIndex_1 (\%) & 27.79 & 16.03 & 27.25 & & 36.31 & 11.46 & 37.62 & \multirow{4}{*}{4,874} \\
\hline & & Degree_1 & 134.0 & 92.9 & 113.5 & \multirow{3}{*}{516} & 137.0 & 88.6 & 119 & \\
\hline & & Constraint_1 & 0.016 & 0.015 & 0.011 & & 0.014 & 0.015 & 0.011 & \\
\hline & & MatchmakerIndex_1 (\%) & 34.08 & 11.76 & 33.99 & & 31.86 & 12.75 & 32.00 & \\
\hline
\end{tabular}

and most integrative are those who began in staff roles and then transitioned to positions in the line. Second, the differences between individuals who stay in line jobs versus in staff jobs is seen in the comparison between the upper left and the lower right quadrants of the tables. We see that stayers in both the corporate headquarters and the corporate sales force (the lower right quadrants) are considerably more central in the communication network than stayers in line jobs (upper left quadrant): the mean stayer-in-line has 104 contacts, compared to 123 for the typical member of the headquarters and 137 for the average member of the corporate sales force. Similarly, stayers-in-line have the fewest structural holes of the groups represented in Table 3 (their mean constraint is 0.031 , compared to 0.018 for $\mathrm{CHQ}$ stayers and 0.014 for CSF stayers) and the lowest matchmaker index $(27.79 \%$, compared to $44.13 \%$ for CHQ stayers and $31.86 \%$ for CSF stayers).

In Table 4, we conclude our cross-sectional analysis by examining differences between the corporate staff and the line organization in a multivariate regression framework. We regress dummy variables indicating whether an individual occupies a CHQ job or a CSF job on dependent variables measuring network characteristics. ${ }^{7}$ Because our theoretical interest is in making comparisons between employees in line and staff jobs, we include in each regression observations for all members of the line organization and either members of the headquarters (Models 1-3) or the sales force (Models 4-6), but not both. Therefore, the comparison made in all regressions is between members of one of the corporate staff groups and members of the line organization. Lastly, we only present the Time 1 network descriptors, again because the conclusions to be drawn are identical in the unreported Time 2 results.

In the cross section, we find that members of both the headquarters and corporate sales units are more central and possess networks that are

\footnotetext{
${ }^{7}$ Because of the possibility that the error terms might be correlated across models, we replicated this analysis using seemingly unrelated regression (SUR). Results were substantively identical, suggesting minimal correlation of error terms across models and increasing our confidence in the robustness of our findings.
} 


\section{A. M. Kleinbaum and T. E. Stuart}

Table 4. Results of multivariate regression of organizational position (CHQ or Corporate Sales) and other covariates on network variables in Time 1

\begin{tabular}{|c|c|c|c|c|c|c|}
\hline \multirow[b]{2}{*}{$\begin{array}{l}\text { Comparison of line against: } \\
\text { DV }\end{array}$} & \multicolumn{3}{|c|}{ Headquarters } & \multicolumn{3}{|c|}{ Corporate sales } \\
\hline & $\begin{array}{l}\text { Degree } \\
\text { (1) }\end{array}$ & $\begin{array}{l}\text { Constraint } \\
\text { (2) }\end{array}$ & $\begin{array}{l}\text { Matchmaker } \\
\text { index } \\
\text { (3) }\end{array}$ & $\begin{array}{l}\text { Degree } \\
\text { (4) }\end{array}$ & $\begin{array}{l}\text { Constraint } \\
\text { (5) }\end{array}$ & $\begin{array}{c}\text { Matchmaker } \\
\text { index } \\
(6)\end{array}$ \\
\hline CHQ_1 & $\begin{array}{c}0.706 \\
(0.102)^{* *}\end{array}$ & $\begin{array}{l}-0.248 \\
(0.020)^{* *}\end{array}$ & $\begin{array}{c}0.656 \\
(0.017)^{* *}\end{array}$ & - & - & - \\
\hline CSF_1 & - & - & - & $\begin{array}{c}1.117 \\
(0.048)^{* *}\end{array}$ & $\begin{array}{l}-0.332 \\
(0.009)^{* *}\end{array}$ & $\begin{array}{c}0.191 \\
(0.010)^{* *}\end{array}$ \\
\hline Female & $\begin{array}{c}0.682 \\
(0.054)^{* *}\end{array}$ & $\begin{array}{l}-0.124 \\
(0.012)^{* *}\end{array}$ & $\begin{array}{l}-0.009 \\
(0.012)\end{array}$ & $\begin{array}{c}0.673 \\
(0.047)^{* *}\end{array}$ & $\begin{array}{l}-0.118 \\
(0.010)^{* *}\end{array}$ & $\begin{array}{l}-0.023 \\
(0.011)^{*}\end{array}$ \\
\hline logTenure & $\begin{array}{c}0.837 \\
(0.028)^{* *}\end{array}$ & $\begin{array}{l}-0.223 \\
(0.007)^{* *}\end{array}$ & $\begin{array}{c}0.130 \\
(0.007)^{* *}\end{array}$ & $\begin{array}{c}0.770 \\
(0.025)^{* *}\end{array}$ & $\begin{array}{l}-0.196 \\
(0.006)^{* *}\end{array}$ & $\begin{array}{c}0.109 \\
(0.006)^{* *}\end{array}$ \\
\hline Exec_1 & $\begin{array}{c}4.261 \\
(0.087)^{* *}\end{array}$ & $\begin{array}{l}-0.692 \\
(0.013)^{* *}\end{array}$ & $\begin{array}{c}0.467 \\
(0.013)^{* *}\end{array}$ & $\begin{array}{c}4.357 \\
(0.081)^{* *}\end{array}$ & $\begin{array}{l}-0.684 \\
(0.012)^{* *}\end{array}$ & $\begin{array}{c}0.432 \\
(0.012)^{* *}\end{array}$ \\
\hline NumMoves_Function & $\begin{array}{c}0.525 \\
(0.026)^{* *}\end{array}$ & $\begin{array}{l}-0.123 \\
(0.005)^{* *}\end{array}$ & $\begin{array}{c}0.059 \\
(0.005)^{* *}\end{array}$ & $\begin{array}{c}0.369 \\
(0.021)^{* *}\end{array}$ & $\begin{array}{l}-0.088 \\
(0.004)^{* *}\end{array}$ & $\begin{array}{c}0.045 \\
(0.004)^{* *}\end{array}$ \\
\hline NumMoves_Office & $\begin{array}{l}-0.105 \\
(0.017)^{* *}\end{array}$ & $\begin{array}{c}0.017 \\
(0.004)^{* *}\end{array}$ & $\begin{array}{c}0.005 \\
(0.004)\end{array}$ & $\begin{array}{l}-0.067 \\
(0.016)^{* *}\end{array}$ & $\begin{array}{c}0.011 \\
(0.003)^{* *}\end{array}$ & $\begin{array}{c}0.004 \\
(0.004)\end{array}$ \\
\hline PctInSample_1 & $\begin{array}{c}8.159 \\
(0.107)^{\text {** }}\end{array}$ & $\begin{array}{c}-1.825 \\
(0.027)^{* *}\end{array}$ & $\begin{array}{c}-0.230 \\
(0.027)^{* *}\end{array}$ & $\begin{array}{c}8.075 \\
(0.099)^{* *}\end{array}$ & $\begin{array}{c}-1.755 \\
(0.024)^{* *}\end{array}$ & $\begin{array}{c}-0.124 \\
(0.025)^{* *}\end{array}$ \\
\hline Constant & $\begin{array}{c}2.265 \\
(0.088)^{* * *}\end{array}$ & $\begin{array}{l}-2.351 \\
(0.023)^{* *}\end{array}$ & $\begin{array}{c}-1.228 \\
(0.027)^{* *}\end{array}$ & $\begin{array}{c}2.517 \\
(0.079)^{* *}\end{array}$ & $\begin{array}{c}-2.468 \\
(0.021)^{* *}\end{array}$ & $\begin{array}{c}-1.215 \\
(0.024)^{* *}\end{array}$ \\
\hline Observations & 18,511 & 18,511 & 18,465 & 22,898 & 22,898 & 22,853 \\
\hline $\mathrm{R}^{2} /$ Log pseudolikelihood & 0.42 & 0.39 & $-7,758.12$ & 0.43 & 0.41 & $-9,629.76$ \\
\hline
\end{tabular}

Similar results obtain in Time 2 .

Robust standard errors in parentheses.

*significant at $5 \%$;*significant at $1 \%$.

less structurally constrained and more integrative compared to members of the line organization. To contextualize the magnitudes of these effects, the CHQ effect is equivalent to a 15 percent increase in degree centrality, a 22 percent decrease in structural constraint, and a remarkable 53 percent increase in the matchmaker index. The CSF effect translates to a 24 percent increase in centrality, a 28 percent decrease in constraint, and a 14 percent increase in the matchmaker index. Therefore, in support of the Baseline Hypothesis, a cross-sectional snapshot of the communication network within BigCo is consistent with - though we do not claim that it is proof of - the classic conceptions of the coordinating role of corporate staff: relative to otherwise similar members of the line, CHQ and CSF members have networks that are better optimized to gather information and to activate coordination initiatives within BigCo.

The control variables are of interest as well. Women in BigCo are more central, more integrative and have more structural holes in their communication networks than do men (see also Kleinbaum et al., 2013). Centrality, structural autonomy and cross-boundary integration also increase with tenure within the company and with executive status, relative to the omitted group of middle managers.

The strong association between staff position and network characteristics begs the question of causality: does occupancy of a staff role cause individuals in the company to develop broader, more integrative networks with more structural holes, as in Hypothesis 1? Or, as implied in the person-based Hypotheses 2 and 3, do members of the corporate staff possess broader networks because individuals are sorted into or screened out of staff roles based, in part, on their networks? We explore this question more thoroughly in the next set of tables. Recall that the estimation strategy unfolds in two stages: in the first, we model the probability that individuals in line roles in Time 1 transition to corporate headquarters or corporate sales positions in Time 2, or vice versa for employees who begin in staff jobs and are 
therefore at risk of transitioning to the line. These regressions, shown in Table 5, are estimated to generate propensity scores, but are also of interest in their own right.

The first three models in Table 5 report estimates of Line-to-CHQ, the probability that employee $i$ transitions to a CHQ job, conditional on beginning in a line job in Time 1. Models 4-6 are estimates of CHQ-to-Line. Models 7-12 are estimated on analogous variables for mobility between the line and the corporate sales force: Line-to-CSF and CSF-to-Line. In other words, this table explores the determinants of individuals' mobility across the staff-line divide for risk sets defined by employees' origin job locations.

The findings indicate that network centrality, structural holes and cross-boundary integration are significantly associated with mobility from line to staff jobs, but the associations are insignificant for mobility in the reverse direction. Results appear in Table 5, Models 1-3 (Line-to-CHQ), as well as 7-9 (Line-to-CSF). Degree centrality (Models 1 and 7) and the matchmaker index (Model 3 and 9) have strong, positive associations with mobility from the line to both staff units, and high structural constraint (an inverse measure of structural holes) decreases the likelihood of line-staff transitions (Models 2 and 8). To provide a sense for magnitudes of the effects of network position on mobility, ceteris paribus, a member of the line organization whose degree centrality is at the 75th percentile of the sample is 56 percent more likely to switch into CHQ and 39 percent more likely to switch into CSF than someone at the 25 th percentile of our sample. The corresponding numbers are 49 and 44 percent, respectively, for constraint (reverse-scored, to measure structural holes) and fully 124 and 93 percent, respectively, for the matchmaker index. We conclude that the magnitudes of the effects of network-based selection into the corporate staff, particularly into the corporate headquarters, are of both practical and statistical significance. These findings support Hypothesis 2: there is evidence of a network-based allocation process, in which individuals with broad networks are more likely to move from jobs in the line to positions in the corporate staff.

Regressions 4-6 (CHQ-to-Line) and 10-12 (CSF-to-Line) in Table 5 show, conversely, the estimated probabilities of moving to line jobs for the individuals who are in the corporate staff in Time 1. In these regressions, just one of the network variables (Model 12) is statistically significant in predicting transitions from the CHQ or the CSF to the line organization; furthermore, its sign (like those of the statistically insignificant coefficients) is the opposite of what Hypothesis 3 would predict. Properties of individuals' communication networks therefore are associated with moving from the line into CHQ and CSF, but play no consistent role in predicting the transition from either unit of the corporate staff to line jobs. In other words, the regressions together tell a story in which there is network-based sorting into the corporate staff such that employees with communication networks that appear to be optimized for coordination are more likely to make the line-staff transition, but conversely, we find no evidence of a weeding-out process in which individuals with narrow networks transition at an accelerated rate from staff to line jobs. Therefore, we reject Hypothesis 3 , the person-based screening hypothesis.

Turning to the control variables, past mobility across other boundaries within the firm, which we include to control for any form of unobserved heterogeneity that drives a general tendency for mobility (Heckman and Borjas, 1980), correlates with the propensity to transition. A count of the number of prior moves between offices or job functions increases the probability of transitioning from the corporate staff to the line and from the line to the corporate sales force but not to CHQ. Ceteris paribus, short-tenured employees are more likely to move from the sales force into the line. On the other hand, executives are more likely to move from the corporate staff into the line and less likely to move into the CSF.

Thus far, we conclude that individuals with broad networks that are optimized for coordination are more likely to move into corporate staff jobs. But is there an additional effect of moving to a corporate staff position on the networks of employees who do move? We address this question in Table 6. The first three models report the effect of Line-to-CHQ, a dummy variable set equal to one for those who transition from the line to corporate headquarters between the observation windows. The comparison group is the set of individuals who began and stayed in jobs in the line organization (i.e., the population that was at risk of switching into staff roles but did not). Models 4-6 report the effect of CHQ-to-Line, a dummy variable set equal to one for those who transition from headquarters to line jobs between 


\section{A. M. Kleinbaum and T. E. Stuart}

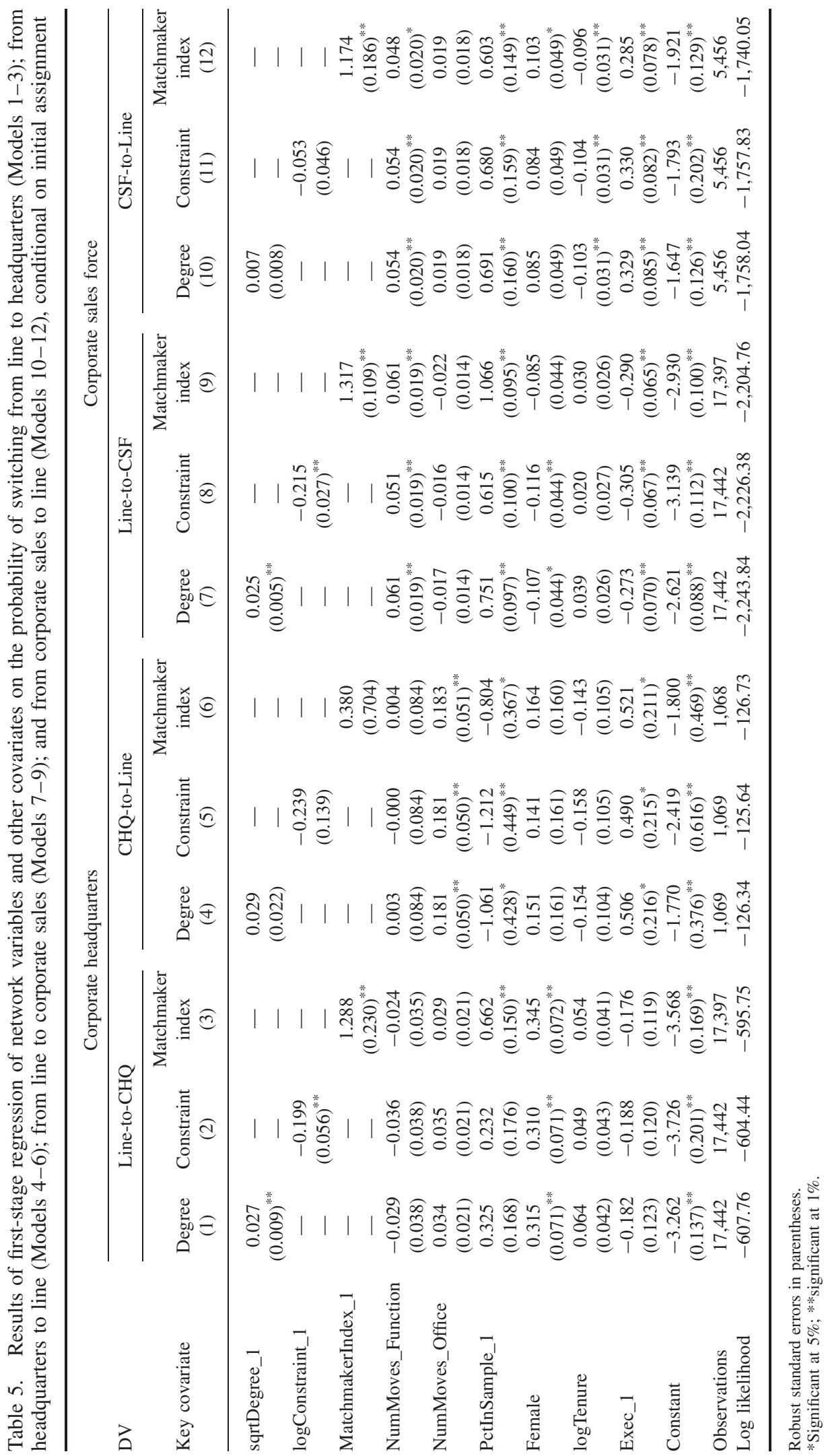


the observation windows. The comparison group is the set of individuals who began and stayed in jobs in the corporate headquarters (i.e., the population that was at risk of switching into line roles but did not). In Models 7-12, we estimate similar effects of transitions between the corporate sales force and the line organization. Recall that we adjust for all observable determinants of mobility, including the network characteristics that serve as the dependent variables in the second-stage regressions, via inverse probability of treatment weights (IPTW).

Table 6 does show effects of moving from line to staff roles on network composition. Line-staff transition is positively related to employees' degree centrality and matchmaker index and negatively related to employee's structural constraint for moves from the line organization to either the corporate headquarters or the corporate sales force (Models 1-3 for CHQ; Models 7-9 for CSF). Thus, as position-based theories of the role of the corporate staff imply, making the transition into either CHQ or CSF leads to increases in employees' network centrality, structural holes, and crossboundary integration, even after accounting for the fact that central individuals with broad, integrative networks are more likely to sort into jobs in CHQ in the first place. This result supports Hypothesis 1.

The results of the effect of transitions from a staff to a line role on Time 2 network characteristics are somewhat surprising given the findings in our first-stage models. Individuals who have broad networks sort into CHQ jobs and their networks appear to expand in consequence, but the reverse is not true: not only is there no indication that individuals with constrained or narrow networks are more likely to move from corporate staff jobs to positions in the line organization, but the transition from the corporate staff to line roles is not associated with any change in network structure. Of our six models of the effect of staff-line transitions on network structure, only Model 12 (the effect of CSF-to-Line on the matchmaker index) is significant, and it is in a direction that runs contrary to what Hypothesis 1 would suggest. (Note, however, that the coefficient magnitudes in the regressions of the matchmaker index are nearly twice as large for moves into the corporate staff than they are for exits from these positions.) Across the sets of regressions in Tables 5 and 6 , by both selection processes and putative treatment effects, moving out of the corporate staff and into the line organization appears to have relatively little impact on the structure of an actor's network. Thus, support for Hypothesis 1 is asymmetric: we find that moving into the headquarters is associated with a broadening of networks, but moving out of the headquarters does not correlate with a focusing of networks.

These findings beg the question, when individual employees move across the line-staff divide, how do their networks change? Specifically, for both movers and stayers, what proportion of each individual's contacts in the Time 1 network remain contacts in the Time 2 period? We are limited by space and information, but a few additional, descriptive views of the data provide a glimpse of this process (for a summary table, see Appendix S3). For stayers in line jobs, the number is 27.2 percent; for stayers in CHQ, it is 30.4 percent (largest with $p<0.01$ ); and for stayers in corporate sales, it is 27.2 percent. These percentages indicate that individuals likely have a core set of contacts who remain constant across time, while the majority of their contacts are engaged in a set of short-term interactions that are of a more episodic nature that shift with the ebb and flow of work tasks.

When we look at movers between line and staff roles, the number of retained contacts falls by about a third $(p<0.01)$. For those who switch from the line into CHQ or CSF jobs, respectively, only 21.8 and 18.7 percent of Time 1 contacts are maintained (or reactivated) a year later. For employees who travel in the opposite direction, from CHQ into Line or CSF into Line, the numbers are, respectively, 22.7 and 19.6 percent. In other words, all individuals at BigCo experience significant changes in their communication networks over time, but the replacement of past contacts with new ones is accelerated for individuals who move across the line-staff divide.

For the small fraction of moves that occur inside the first three-month e-mail window in Q4 2006, we can gain additional insight into the rate at which the members of an individual's network turn over as a consequence of moving. Figure 2 displays these data. Specifically, we constructed two charts showing the percentage of an individual's total communications that are exchanged with members of the corporate headquarters (a) or the sales organization (b) during the period surrounding a job change. In each chart, we show weekly percentages for two different populations: 


\section{A. M. Kleinbaum and T. E. Stuart}

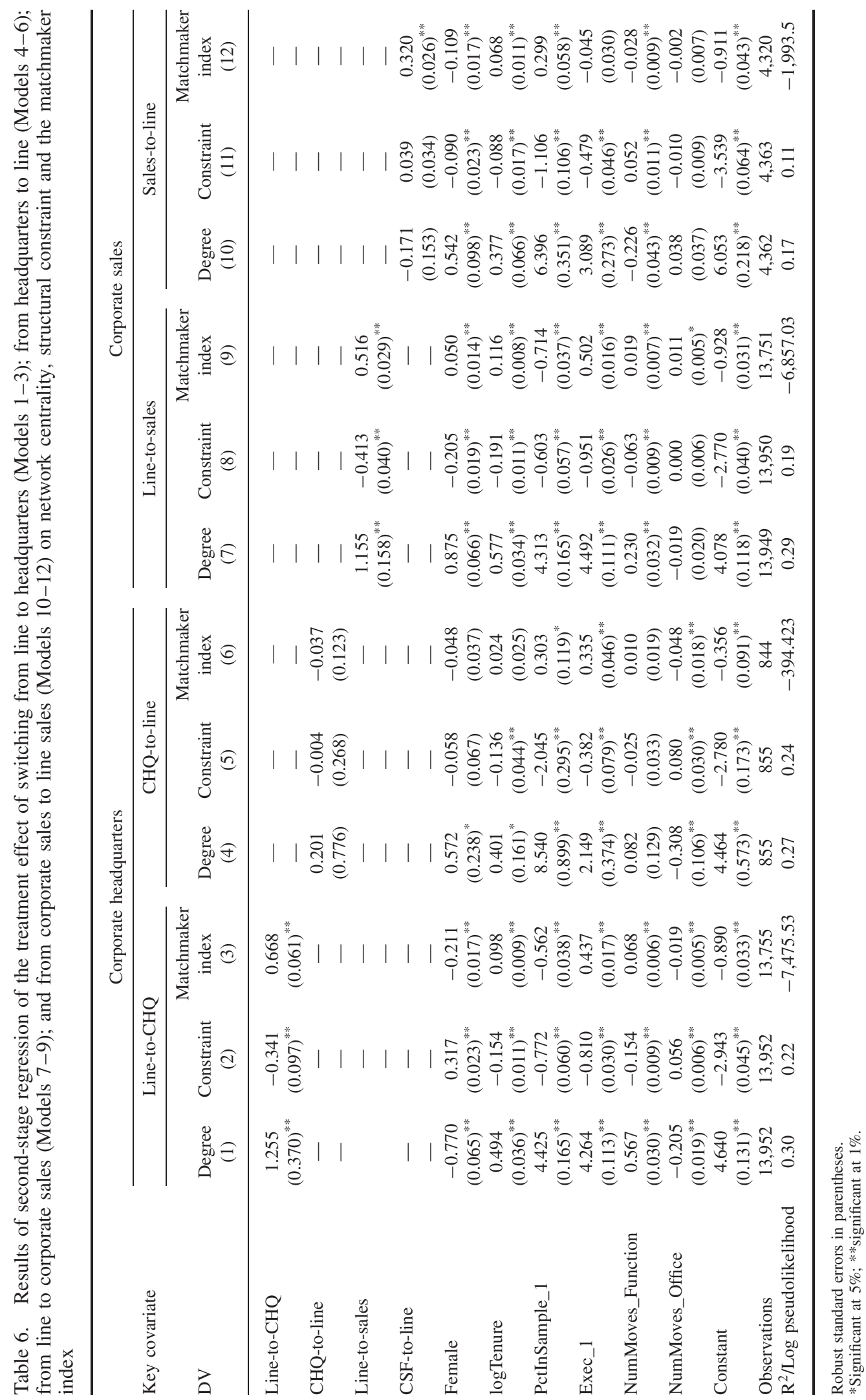


Inside the Black Box of the Corporate Staff

people who transition from line to staff and those who move in the opposite direction during the month of November 2006. We focus on this month because this is the middle month in the first tranche of e-mail data, so we can examine communication patterns both before and after the transition. To see how the transition unfolds over a longer interval of time, we then append a final data point from the Time 2 window of e-mail data, corresponding to the first quarter of 2008. This final point most likely approximates an individual's steadystate, post-transition rate of communicating within each represented group. Each chart also includes upper and lower bounds, indicating the overall email patterns of employees who stay in the line organization (lower) or the corporate staff (upper) throughout the observation period, spanning from late 2006 through early 2008.

The upper bound in Figure 2(a) shows that for stayers in CHQ, approximately 65 percent of their interactions occur with other individuals in CHQ. The lower bound indicates that for stayers in the line organization, only about 2.5 percent of their total interactions occur with members of headquarters. The dotted, upward sloping curve shows, for individuals who switch from line to CHQ jobs in November 2006, the weekly percentage of e-mail interactions with members of the corporate staff. The most important point to draw from the figure is that there appears to be a relatively quick shift in communication partners upon job changes, but even a full year later, movers have networks that are less concentrated within the line or staff than colleagues who do not move. For instance, one month after their move to CHQ, former members of the line already have shifted approximately 45 percent of their interaction to CHQ (versus $2.5 \%$ for a typical member of the line organization at baseline). A little more than a year later, this number increases to 60 percent, but it is still below the 65 percent level for employees who began and remained in staff jobs. For individuals who move from CHQ to the line organization (dashed line), within-CHQ communications drop below 20 percent by the second week after the move and fall to about 10 percent at the end of our observation window. Once again, the data show a relatively quick shift in network composition, but they also suggest that individuals who move from headquarters retain more contacts in CHQ than do typical members of the line organization.

\section{DISCUSSION AND CONCLUSION}

Theories of the multidivisional firm place significant emphasis on the role of the corporate staff, but empirical research on the staff's function is limited. In an analysis of e-mail communications, we begin to open the black box of the corporate staff to reveal its internal wiring. We know from the literature that coordination among autonomous operating units is one of the central purposes of the corporate headquarters and other corporate-level staff units. Consistent with this work, we find that members of the corporate staff have broad, unconstrained networks that frequently stitch together colleagues from different business units.

To understand the differences in network structure between members of the staff and the line organization, we attempt to separate a process of nonrandom selection or assignment from a true treatment effect. We exploit HR data on intrafirm mobility and the temporal dimension of the email data to study how communication networks change when employees transition, in both directions, between the line organization and either the headquarters unit or the corporate sales force. We present evidence that the differences in network structure between members of the line organization and the corporate staff stem partially from the structure of the organization per se but also result from a sorting process that assigns individuals with broader networks to corporate staff roles. We find no evidence that people with narrow, closed networks vacate corporate staff jobs to join the line organization.

Taken together, our findings hint at the presence of a 'corporate imprimatur' effect, in which people with broader networks move into corporate staff roles; the move to the corporate staff then further broadens individuals' networks; and individuals who have cultivated broad networks in corporate staff jobs retain this general network structure even if they return to the line organization. Interestingly, there is rapid turnover in the specific contacts in employees' networks following instances of job mobility, but although most individual contacts change, the overall shape of employees' egocentric networks - their levels of centrality, cross-boundary integration, and constraint-may be permanently influenced by employment spells in the corporate staff.

This research has a number of limitations that merit mention. First, despite the large quantity 
(a)

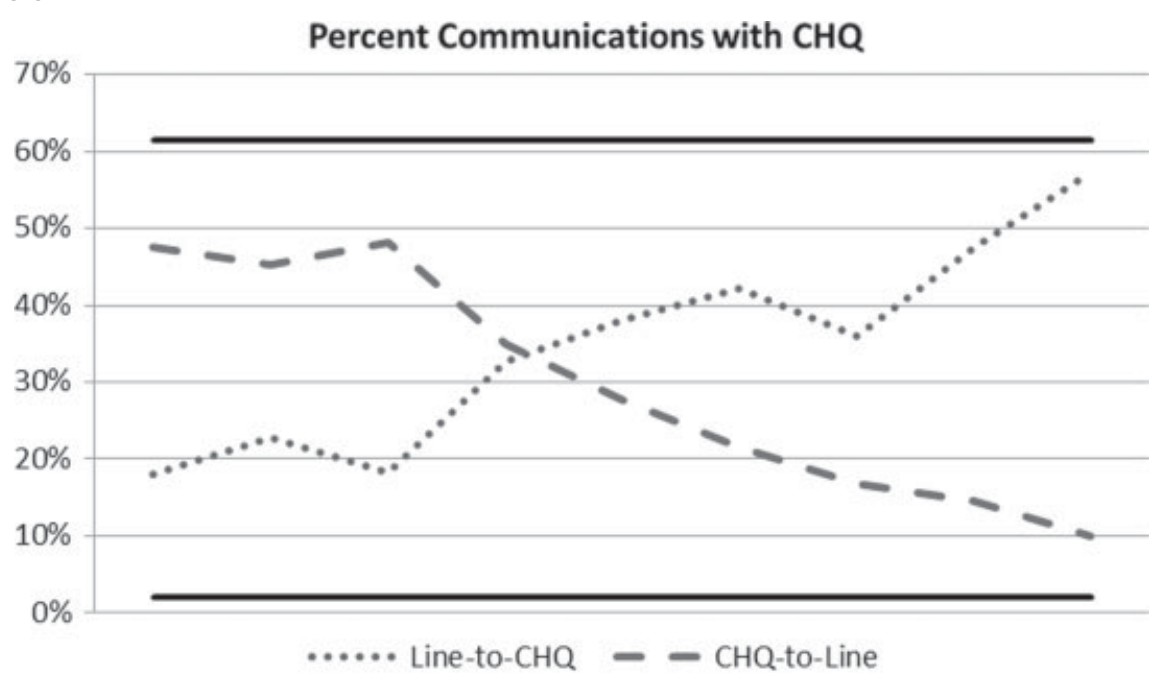

(b)

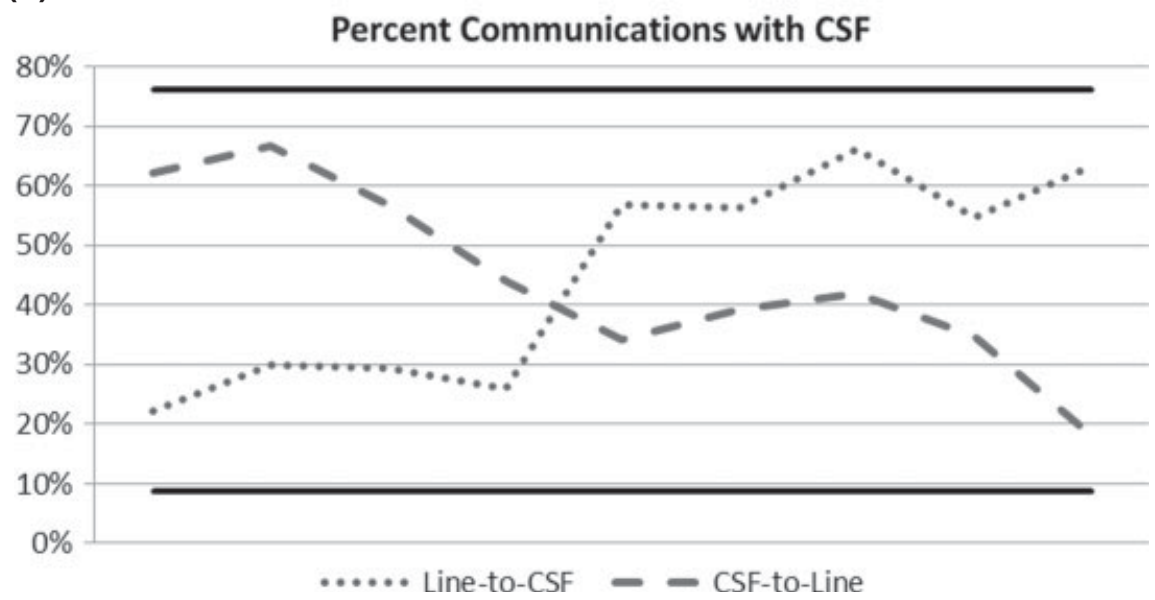

Figure 2. Weekly communication patterns among employees who change jobs between the corporate staff (headquarters and sales force) and the line organization during the month of November 2006. (a) Switchers between positions in Corporate Headquarters and the line organization. (b) Switchers between positions in the Corporate Sales

Force and the line organization

of e-mail data, this is a case study of one firm. We have no basis on which to claim that the findings are generalizable to other organizations. The company we study is one with many, related business units. Our field interviews underscore that members of both headquarters and the corporate sales force are intended to coordinate actively across SBUs. As such, we believe that BigCo is a typical example of the category of large, relateddiversified firm. If it pursues coordination more vigorously than other such firms, we would guess that this difference in more a matter of extent than of kind. However, this is a conjecture; the data do not allow us to generalize beyond this single case.

Second, our analysis is limited by the relatively small number of people who exit the corporate headquarters to return to the line organization during the observation window. Despite the small number of job changes, the parameters on the effects of CHQ-to-line mobility are estimated with a reasonable level of precision. Nevertheless, given the small number of mobility events, it is difficult 
to know if the results may be idiosyncratic to movers in some way that is not addressed by the covariates used to compute the propensity scores.

Third, although our argument that members of the corporate staff should have larger, sparser, and more integrative networks than those in the line organization rests on the presumption that a central role of the corporate staff is coordination, we do not observe coordination directly. Rather, coordination is the unobserved mechanism that drives our baseline hypothesis. The fact that the hypothesis is supported provides evidence consistent with the coordinating role of the corporate center, but it does not prove the point. Future research could explore this mechanism more directly by, for example, linking the network variables that we develop to measures of coordination quality at the individual or team level. More generally, this point suggests that network structure may be a necessary, but insufficient, condition for just about any outcome. We might reasonably assert that for an actor to coordinate the actions of two others, she must be connected to them both, but the converse is not true: connection does not necessarily imply coordination. Future research should move beyond network structure to take more seriously the role of agency in networks (Burt, 2010: 221-227).

Fourth, we are intrigued by the question of how individuals' career strategies interplay with the findings in the paper, but we are unable to address the issue directly with the data available to us. For instance, dating at least back to Kanter (1977), we have known that job spells in corporatelevel units may be beneficial for managers' career prospects. Kanter writes, '[People moving to the headquarters] would have exposure and make connections that would further their careers. No one ever advances who had not spent some time in headquarters,' (Kanter, 1977: 33). In essence, via 'exposure and connections,' Kanter argues that there is a causal effect of being in headquarters on one's network structure. This is consistent with the findings of our study, but it also underscores the role of deliberate career strategies in the types of mobility events that we observe and analyze. It is distinctly possible that transitions to the corporate staff, and the associated network structures, are the result of specific and deliberate career trajectories (Kleinbaum, 2012).

A related shortcoming is that distinguishing between position-based and person-based explanations gets us only part of the way to an understanding of true, causal mechanisms. In the case of job mobility, we do not know, for instance, to what extent the matching of broad networks to staff roles is a consequence of selection by the company of individuals into specific roles or of self-selection by individual employees to jobs that match their social capital profiles, or both. Alternatively, if some people in the line organization play coordinating, liaison-type roles within their divisions, those roles could be associated both with broader networks than the typical manager and with a higher probability of mobility into the corporate staff. Under this scenario, the results are explained by a persistent division of labor in the organization, in which a subset of the managerial population consistently sorts into coordinationfocused job roles, rather than by person-based explanations.

\section{Contributions and implications}

Despite these limitations, we make several contributions to the literature. First, our results raise questions about the conventional wisdom regarding the primacy of structure in the implementation of corporate strategy. We find evidence that structure matters: the results suggest that assigning someone to the corporate center has a causal effect on the structure of her network. However, we also find that selection of who populates corporate-level organizational units is critical. Our results show that employees either sort or are selected into different roles based in part on the structure of their networks: employees with broader, sparser, more integrative networks are more likely to transition into the corporate staff. In fact, our results may suggest that there is a corporate staff type. There is a long history of research showing that people sort into different organizational roles based on ascribed characteristics (Bielby and Baron, 1986), but ours is the first study we know of that offers evidence of systematic sorting of people into corporate staff roles. This finding is particularly important because it raises the possibility that having the right lateral coordinating structures in place may not be sufficient to realize fully the coordination benefits of a diversified corporate strategy. There may be additional benefit to populating those structures with the right people - namely, 'corporate types' who are more prone to create broad networks. Additional research is needed to verify 


\section{A. M. Kleinbaum and T. E. Stuart}

these suggestions; as such, we posit that research on the social structure of the corporation is more important to the study of strategy implementation than has been recognized.

Second, our results suggest that formal organizational structure sometimes - but only sometimes - has the intended effect on networks. Tom Allen, echoing Thompson (1967), has argued, 'The real goal of formal organization is the structuring of communication patterns,' (Allen, 1977: 211). If this assertion is accurate and if the role of headquarters is to coordinate the activities of a disparate set of actors in the line organization, our results suggest that moving people into the corporate staff has the intended effect: it serves to broaden their networks. But we also find that moving people out of the corporate staff does not serve to focus their networks more narrowly. A tentative conclusion from our results, like those of Gulati and Puranam (2009) and Corredoira and Rosenkopf (2010), might be that formal structure appears better suited to facilitate the formation of ties than the dissolution of ties.

An alternative possibility exists, however: perhaps the reason networks do not shrink when individuals move from the staff into the line is because even if their formal roles become less focused on coordination, they nevertheless can still provide value to the organization through informal coordination. This explanation for the unexpected asymmetry in our results for Hypothesis 1 would be consistent with theoretical work on the inherent imperfection of formal structure (Galbraith, 1973) and the valuable, compensating role of social structure (Kleinbaum and Tushman, 2007). We leave it for future research to determine the extent to which each of these possibilities explains the persistence of ties.

Third, we make a contribution by developing the construct of cross-boundary integration and its measure, the matchmaker index. While the measure is simple, we believe that it is a useful summary statistic for the degree to which an individual is positioned to integrate across organizational boundaries within firms. There is a voluminous literature on intraorganizational networks that employs the construct of structural holes, and we have no doubt that brokerage is a very important phenomenon with well-documented consequences. But other network phenomena, such as coordination, have been studied less extensively. And while previous scholars have described structures (Gould and Fernandez, 1989) and psychological orientations (Obstfeld, 2005) related to the phenomenon of network-based mediation, the lack of a simple measure has limited progress. By contributing the matchmaker index, we hope to stimulate new avenues of research. We begin that task here by examining the network-based origins of coordination by the corporate staff.

We conclude with reference to Rumelt, Schendel, and Teece's (1994) research agenda for the field of strategy. They identify four fundamental questions to animate research in the field. One of the four questions asks, 'What are the functions of the headquarters unit in a multibusiness firm?' Obviously, one answer to this question is that CHQ drives coordination between operating units in the M-form, but the important antecedent concerns the mechanisms through which this coordination is achieved. We suggest that the final, and broadest, contribution of this study is to provide a rare empirical glimpse inside the black box of the corporate staff as a small step along the road to understanding how coordination may occur in modern, complex organizations.

\section{ACKNOWLEDGEMENTS}

The authors are grateful to Pierre Azoulay, Amanda Cowen, Connie Helfat, Andy King, Margie Peteraf, Mike Tushman, Paul Wolfson, Associate Editor Steven Floyd, two anonymous SMJ reviewers, and seminar participants at Columbia, Dartmouth, and Stanford for valuable comments and suggestions on this paper. Any remaining errors are entirely our own.

\section{REFERENCES}

Allen TJ. 1977. Managing the Flow of Technology: Technology Transfer and the Dissemination of Technological Information Within the R\&D Organization. MIT Press: Cambridge, MA.

Andrews KR. 1971. The Concept of Corporate Strategy. Dow Jones-Irwin: Homewood, IL.

Ansoff HI. 1965. Corporate Strategy; an Analytic Approach to Business Policy for Growth and Expansion. McGraw-Hill: New York.

Azoulay P, Ding W, Stuart TE. 2009. The impact of academic patenting on the rate, quality, and direction of (public) research output. Journal of Industrial Economics 57(4): 637-676. 
Bielby WT, Baron JN. 1986. Men and women at work: sex segregation and statistical discrimination. American Journal of Sociology 91(4): 759-799.

Bonacich P. 1987. Power and centrality: a family of measures. American Journal of Sociology 92(5): $1170-1182$.

Borgatti SP, Everett MG, Freeman LC. 2006. UCINet VI for Windows: Software for Social Network Analysis, Version. Analytic Technologies: Cambridge, MA.

Bourgeois LJ, Brodwin DR. 1984. Strategic implementation: five approaches to an elusive phenomenon. Strategic Management Journal 5(3): 241-264.

Bower JL. 1970. Managing the Resource Allocation Process: a Study of Corporate Planning and Investment (2nd edn). Graduate School of Business Administration, Harvard University: Boston, MA.

Bowman EH, Helfat CE. 2001. Does corporate strategy matter? Strategic Management Journal 22(1): 1.

Burt RS. 1992. Structural Holes: The Social Structure of Competition. Harvard University Press: Cambridge, MA.

Burt RS. 2010. Neighbor Networks: Competitive Advantage Local and Personal. Oxford University Press: Oxford, UK.

Chandler AD. 1962. Strategy and Structure: Chapters in the History of the Industrial Enterprise. MIT Press: Cambridge, MA.

Chandler AD. 1990. Scale and Scope: the Dynamics of Industrial Capitalism. Belknap Press of Harvard University Press: Cambridge, MA.

Coleman JS. 1988. Social capital in the creation of human capital. American Journal of Sociology 94: S95-S120.

Collis DJ, Young D, Goold M. 2007. The size, structure, and performance of corporate headquarters. Strategic Management Journal 28(4): 383-405.

Corredoira RA, Rosenkopf L. 2010. Should auld acquaintance be forgot? The reverse transfer of knowledge through mobility ties. Strategic Management Journal 31(2): 159-181.

Dehejia RH, Wahba S. 2002. Propensity score-matching methods for nonexperimental causal studies. Review of Economics and Statistics 84(1): 151-161.

Eisenhardt KM. 1989. Building theories from case study research. Academy of Management Review 14(4): $532-550$.

Feld SL. 1981. The focused organization of social ties. American Journal of Sociology 86(5): 1015-1035.

Fligstein N. 2001. The Architecture of Markets: An Economic Sociology of Twenty-First-Century Capitalist Societies. Princeton University Press: Princeton, NJ.

Foss NJ. 1997. On the rationales of corporate headquarters. Industrial and Corporate Change 6(2): 313-338.

Freeman LC. 1979. Centrality in social networks: conceptual clarification. Social Networks 1: 215-239.

Galbraith JR. 1973. Designing Complex Organizations. Addison-Wesley: Reading, MA.

Galbraith JR, Nathanson DA. 1978. Strategy Implementation: The Role of Structure and Process. West: St. Paul, MN.

Ghoshal S, Bartlett CA. 1990. The multinational corporation as an interorganizational network. Academy of Management Review 15(4): 603-625.
Ghoshal S, Korine H, Szulanski G. 1994. Interunit communication in multinational corporations. Management Science 40(1): 96-110.

Goold M, Campbell A. 1987. Strategies and Styles: The Role of the Centre in Managing Diversified Corporations. Basil Blackwell: Oxford, UK; New York.

Goold M, Campbell A, Alexander M. 1994. CorporateLevel Strategy: Creating Value in the Multibusiness Company. Wiley: New York.

Gould RV, Fernandez RM. 1989. Structures of mediation: a formal approach to brokerage in transaction networks. Sociological Methodology 19: 89-126.

Govindarajan V. 1986. Decentralization, strategy, and effectiveness of strategic business units in multibusiness organizations. Academy of Management Review 11(4): 844-856.

Gulati R, Puranam P. 2009. Renewal through reorganization: the value of inconsistencies between formal and informal organization. Organization Science 20(2): 422-440.

Gupta AK, Govindarajan V. 1984. Business unit strategy, managerial characteristics, and business unit effectiveness at strategy implementation. Academy of Management Journal 27(1): 25-41.

Handcock MS, Hunter DR, Butts CT, Goodreau SM, Morris M. 2008. Statnet: software tools for the representation, visualization, analysis and simulation of network data. Journal of Statistical Software Available at: http://www.jstatsoft.org/v24/i01/paper/ (accessed 17 April 2013).

Heckman JJ, Borjas GJ. 1980. Does unemployment cause future unemployment? Definitions, questions and answers from a continuous time model of heterogeneity and state dependence. Economica 47(187): 247-283.

Hernán MÁ, Brumback B, Robins JM. 2000. Marginal structural models to estimate the causal effect of zidovudine on the survival of HIV-positive men. Epidemiology 11(5): 561-570.

Kanter RM. 1977. Men and Women of the Corporation. Basic Books: New York.

Khanna T, Palepu K. 2000. The future of business groups in emerging markets: long-run evidence from Chile. Academy of Management Journal 43(3): 268-285.

Kleinbaum AM. 2012. Organizational misfits and the origins of brokerage in intrafirm networks. Administrative Science Quarterly 57(3): 407-452.

Kleinbaum AM, Jordan AH, Audia P. 2012. Do you read me? How perceptions of empathy shape selfmonitors' brokerage in social networks. Tuck Working paper, Dartmouth College. Available at: http://ssrn. com/abstract $=2134566$ (accessed 31 October 2012).

Kleinbaum AM, Stuart TE, Tushman ML. 2013. Discretion within constraint: homophily and structure in a formal organization. Organization Science Available at: http://orgsci.journal.informs.org/content/ early/2013/02/08/orsc.1120.0804.abstract (accessed 9 February 2013).

Kleinbaum AM, Tushman ML. 2007. Building bridges: the social structure of interdependent innovation. Strategic Entrepreneurship Journal 1(1): 103-122. 
Kogut B, Zander U. 1992. Knowledge of the firm, combinative capabilities, and the replication of technology. Organization Science 3(3, Focused Issue: Management of Technology): 383-397.

Lorsch JW, Morse JJ. 1974. Organizations and their Members: A Contingency Approach. Harper \& Row: New York.

Marmaros D, Sacerdote B. 2006. How do friendships form? Quarterly Journal of Economics 121(1): 79-119.

Montgomery CA. 1994. Corporate diversification. Journal of Economic Perspectives 8(3): 163-178.

Nochur KS, Allen TJ. 1992. Do nominated boundary spanners become effective technological gatekeepers? IEEE Transactions on Engineering Management 39(3): 265-269.

Nohria N, Ghoshal S. 1994. Differentiated fit and shared values: alternatives for managing headquarterssubsidiary relations. Strategic Management Journal 15(6): 491-502.

Obstfeld D. 2005. Social networks, the Tertius Iungens orientation, and involvement in innovation. Administrative Science Quarterly 50(1): 100-130.

Ouchi WG. 1980. Markets, bureaucracies, and clans. Administrative Science Quarterly 25(1): 129-141.

Papke LE, Wooldridge JM. 1996. Econometric methods for fractional response variables with an application to $401(\mathrm{~K})$ plan participation rates. Journal of Applied Econometrics 11(6): 619-632.

Parsons T. 1956. Suggestions for a sociological approach to the theory of organizations-I. Administrative Science Quarterly 1: 63-85.

Penrose ET. 1959. The Theory of the Growth of the Firm (1995 edn). Oxford University Press: Oxford, UK.

Powell WW. 1990. Neither market nor hierarchy: network forms of organization. In Research in Organizational Behavior (Volume 12), Staw BM, Cummings LL (eds). JAI Press: Greenwich, CT; 295-336.

Quintane E, Kleinbaum AM. 2011. Matter over mind? E-mail data and the measurement of social networks. Connections 31(1): 22-46.

R Development Core Team. 2010. R: A Language and Environment for Statistical Computing, Version 2.11.1. $\mathrm{R}$ Foundation for Statistical Computing: Vienna, Austria.

Robins JM. 1999. Marginal structural models versus structural nested models as tools for causal inference. In Statistical Models in Epidemiology: The Environment and Clinical Trials, Halloran ME, Barry D (eds). Springer-Verlag: New York.

Rosenbaum PR, Rubin DB. 1984. Reducing bias in observational studies using subclassification on the propensity score. Journal of the American Statistical Association 79(387): 516-524.

Rubin DB. 1977. Assignment to treatment group on the basis of a covariate. Journal of Educational Statistics 2(1): $1-26$.
Rumelt RP, Schendel D, Teece DJ. 1994. Fundamental Issues in Strategy : A Research Agenda. HBS Press: Boston, MA.

Sasovova Z, Mehra A, Borgatti SP, Schippers MC. 2010. Network churn: the effects of self-monitoring personality on brokerage dynamics. Administrative Science Quarterly 55(4): 639-670.

Simmel G. 1902. The Sociology of Georg Simmel (1950 edn). Wolff KH (Trans.) Free Press: Glencoe, IL.

Thompson JD. 1967. Organizations in Action; Social Science Bases of Administrative Theory. Transaction: New Brunswick, NJ.

Tushman ML, Katz R. 1980. External communication and project performance: an investigation into the role of gatekeepers. Management Science 26(11): $1071-1085$.

Villalonga B. 2004. Diversification discount or premium? New evidence from the business information tracking series. Journal of Finance 59(2): 479-506.

Wasserman S, Faust K. 1994. Social Network Analysis: Methods and Applications. Cambridge University Press: New York.

Williamson OE. 1975. Markets and Hierarchies, Analysis and Antitrust Implications: A Study in the Economics of Internal Organization. Free Press: New York.

Wuchty S, Uzzi B. 2011. Human communication dynamics in digital footsteps: a study of the agreement between self-reported ties and e-mail networks. PLoS ONE 6(11): e26972.

Zipf GK. 1949. Human Behavior and the Principle of Least Effort: An Introduction to Human Ecology. Addison-Wesley: Cambridge, MA.

\section{SUPPORTING INFORMATION}

\section{Additional supporting information may be found in the online version of this article:}

Appendix S1: Sample

Appendix S2: Summary statistics and correlation matrix for Time 1 data

Appendix S3: The proportion of the average individual's Time 1 contacts retained in Time 2, reported for categories of employees defined by job at both Time 1 and Time 2. The 'staff' categories refer specifically to either CHQ or CSF, as indicated in the headers of data columns, not to CHQ and CSF combined 


\section{Online Appendix}

to

\section{Inside the Black Box of the Corporate Staff: Social Networks and the Implementation of Corporate Strategy}

\section{Appendix 1: Sample}

We refer to the 30,328 people about whom we received data from BigCo as the 'full sample.' All internal e-mail information that was on the server at the times of data collection was included in our data set. BigCo provided the data in the form of 30,328 text files for each observation period, each representing the communication activity of a single person, which we then cleaned and parsed. To protect the privacy of individual employees, messages were stripped of all content, leaving only information about the sender, recipient(s) and time/date sent. The names of senders and recipients were replaced with encrypted identifiers. We consolidated these files and expanded each multiple-recipient message to include one entry for each unique dyad during each observation period. The complete data set contains 268 million dyadic e-mail communications across the two observation periods.

The sample contains 24 percent of the firm's U.S. employee population and was collected through a snowball sampling procedure. Our initial point of entry into the organization was the corporate sales force: we invited 180 people to participate in the study. Of these 180, about half worked in the corporate sales force itself. Members of the other half were nominated by managers in the sales force, but they held jobs distributed throughout the organizational units of the company. Of the total group, 91 individuals agreed to participate, 25 of whom we were unable to include because they worked outside the U.S. ${ }^{1}$ In turn, the remaining 66 individuals

\footnotetext{
${ }^{1}$ Unfortunately, the sample is limited to U.S-based employees because laws protecting employee privacy effectively precluded collection of this sort of data in much of Europe and parts of Asia.
} 
(we term this group the 'core sample') communicated with an additional 30,262 U.S. employees. The company then provided complete e-mail data for all 30,328 U.S.-based employees (the 66 core sample members and their 30,262 direct contacts).

Although this is not a true random sample, it is compellingly large and the sampling procedure assures that we have a very broad cross section of BigCo employees. This is because BigCo provided complete e-mail records for all individuals who were directly linked to one or more of the 66 individuals in the core sample, which casts a wide net in sweeping people into the sample. An example illustrates why: one of the 66 individuals in the core sample received a mass e-mail that was sent to him and 1,214 co-recipients. This single message accounts for over 4 percent of our full sample because the sampling procedure sweeps the complete e-mail records of the sender and all 1,214 co-recipients into our dataset. In fact, the 66 individuals in the core sample possess an average of 3,415 direct contacts in the full sample, although the vast majority of these contacts exchange only mass e-mails. In short, given the protocol for recruiting the sample, we believe that the presence of widely distributed bulk e-mails ${ }^{2}$ comes close to generating a random sample. ${ }^{3}$

We narrow our sample by excluding 3,107 people because they were administrative assistants, rank-and-file employees ${ }^{4}$, or because they left the firm before the end of the observation window. We also drop from the full sample 350 people who changed jobs multiple

\footnotetext{
${ }^{2}$ Because these large-scale announcements may play a valuable role in coordination, we include them in our analysis, even as we acknowledge that they may not represent interactions that are socially meaningful. Results are substantively identical if we exclude mass e-mails, robustly defined by various thresholds.

${ }^{3}$ In another project (Kleinbaum, 2012), we have gone to great lengths to address any potential bias that might arise from our snowball sampling procedure. Specifically, we exploited the large sample size (30,328 people) by drawing a set of stratified random sub-samples from the full sample. When we do this, every analysis we have performed to date on a sub-sample has produced substantively similar results between the full sample and the random sub-sample. We cannot know it to be definitively true, but given this fact, along with the fact that extensive, cross-cutting email distribution lists were used to recruit most of the members of the overall sample, we think it likely that the full sample is nearly random. Unfortunately, we cannot employ the random sub-sample in the present analysis because our focus on such a small sub-population (namely, people who move between line and staff jobs during a relatively short interval of time) makes drawing sub-samples infeasible. The number of mobility events is sufficiently few that we need to preserve the entire sample for this analysis.

${ }^{4}$ We excluded rank-and-file employees from our sample because they are significantly under-represented in our data set. We suspect, but cannot confirm, that they are under-represented in part because many of them play purely support, technical or non-managerial roles (e.g., custodial staff, assembly line, etc.) that caused them to be excluded from our snowball sampling strategy. For theoretical clarity we focus on the managerial population. However, all results are substantively unchanged if we include rank-and-file employees in the analysis.
} 
times or moved within the corporate staff. ${ }^{5}$ For the remaining people, we drop all

communications that occurred before our observation period, because the availability of such messages may depend on individual e-mail quotas and retention practices.

\footnotetext{
${ }^{5}$ These 350 include 25 people who switched from corporate sales to the headquarters unit and 20 people who moved in the opposite direction, from CHQ to CSF. Because these are moves within the corporate staff, we exclude these mobility events from the analysis. We also drop from our sample 306 people who changed jobs multiple times during the observation window, many of whom cycle back and forth between staff and line jobs. Our concern is that these individuals are on temporary job assignments and therefore it is unclear what mobility means in these instances.
} 
Appendix 2: Summary Statistics and Correlation Matrix for Time 1 data

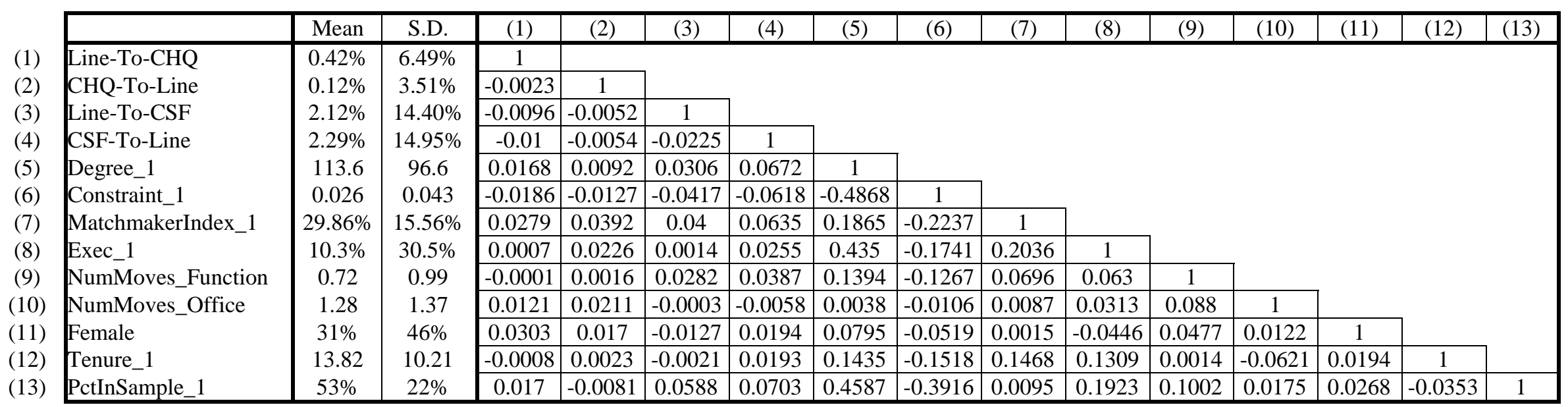


Appendix 3: The proportion of the average individual's Time 1 contacts retained in Time 2, reported for categories of employees defined by job at both Time 1 and Time 2. The 'staff' categories refer specifically to either CHQ or CSF, as indicated in the headers of data columns, not to CHQ and CSF combined.

\begin{tabular}{|l|c|c|c|}
\hline & Category & Corporate Headquarters & Corporate Sales Force \\
\hline$(1)$ & Stayers-in-Line & $27.2 \%$ & $27.2 \%$ \\
$(2)$ & Line-to-Staff & $21.8 \%$ & $18.7 \%$ \\
$(3)$ & Staff-to-Line & $22.7 \%$ & $19.6 \%$ \\
(4) & Stayers-in-Staff & $30.4 \%$ & $27.2 \%$ \\
\hline
\end{tabular}

Notes: Student's t-tests indicate that within the Corporate Headquarters column, the difference between groups (2) and (3) is statistically insignificant; the difference between groups (1) and (3) is significant with $\mathrm{p}<$ 0.05 ; all other differences are significant with $\mathrm{p}<0.01$. Within the Corporate Sales Force column, differences are insignificant between groups (1) and (4) and between groups (2) and (3); all other differences are significant with $\mathrm{p}<$ 0.01 .

Looking across rows, group (1) consists of the same people across columns by construction, so no test was performed; groups (2) and (4) are significantly different across columns with $\mathrm{p}<0.01$; group (3) is significantly different across columns with $\mathrm{p}<0.07$. 